\title{
Numerical Simulation of Atmospheric Response to Pacific Tropical Instability Waves*
}

\author{
R. JUSTIN SMALL \\ International Pacific Research Center, School of Ocean and Earth Science and Technology, University of Hawaii at Manoa, \\ Honolulu, Hawaii \\ SHANG-PING XIE \\ Department of Meteorology, School of Ocean and Earth Science and Technology, University of Hawaii at Manoa, Honolulu, Hawaii
}

YUQING WANG

International Pacific Research Center, School of Ocean and Earth Science and Technology, University of Hawaii at Manoa, Honolulu, Hawaii

(Manuscript received 22 November 2002, in final form 21 March 2003)

\section{ABSTRACT}

\begin{abstract}
Tropical instability waves (TIWs) are 1000-km-long waves that appear along the sea surface temperature (SST) front of the equatorial cold tongue in the eastern Pacific. The study investigates the atmospheric planetary boundary layer (PBL) response to TIW-induced SST variations using a high-resolution regional climate model. An investigation is made of the importance of pressure gradients induced by changes in air temperature and moisture, and vertical mixing, which is parameterized in the model by a 1.5-level turbulence closure scheme. Significant turbulent flux anomalies of sensible and latent heat are caused by changes in the air-sea temperature and moisture differences induced by the TIWs. Horizontal advection leads to the occurrence of the air temperature and moisture extrema downwind of the SST extrema. High and low hydrostatic surface pressures are then located downwind of the cold and warm SST patches, respectively. The maximum and minimum wind speeds occur in phase with SST, and a thermally direct circulation is created. The momentum budget indicates that pressure gradient, vertical mixing, and horizontal advection dominate. In the PBL the vertical mixing acts as a frictional drag on the pressure-gradient-driven winds. Over warm SST the mixed layer deepens relative to over cold SST. The model simulations of the phase and amplitude of wind velocity, wind convergence, and column-integrated water vapor perturbations due to TIWs are similar to those observed from satellite and in situ data.
\end{abstract}

\section{Introduction}

The atmospheric PBL response to SST in the tropical Pacific was studied by Lindzen and Nigam (1987, hereafter LN). They proposed that the SST variation induces direct changes in the air temperature above and thus a pressure change in the atmosphere, through hydrostatic balance, so that near-equatorial winds converged onto warm SST patches and diverged from cold SST patches. This theory is based on an assumption that the tropical air masses are well mixed up to the inversion layer, due

\footnotetext{
* International Pacific Research Center Contribution Number 213 and School of Ocean and Earth Science and Technology Contribution Number 6230.

Corresponding author address: Dr. R. Justin Small, International Pacific Research Center, School of Ocean and Earth Science and Technology, POST 413, 2525 Correa Rd., University of Hawaii at Manoa, Honolulu, Hawaii 96822.

E-mail: small@hawaii.edu
}

to buoyant fluxes from the sea surface, and consequently the air temperature and hydrostatic pressure are directly related to the underlying SST. They quantified their theory with a vertically integrated linear mixed layer model. Reasonable results were obtained when the PBL height was allowed to vary in response to the cumulus mass flux associated with low-level convergence.

Wallace et al. (1989) and Hayes et al. (1989, hereafter HMW) went on to further study the effect of SST gradients on surface winds in the eastern tropical Pacific. Wallace et al. found that on seasonal and interannual timescales the meridional component of the trade winds was correlated with the SST in the cold tongue, and proposed that this was because the high winds aloft were decoupled from surface winds in the presence of more stable stratification over cold SST. Over warmer SST the boundary layer was less stable, inducing vertical mixing and reduction of shear, leading to a more uniform velocity profile with higher winds at the surface than over cold SST. Under this explanation the winds are $90^{\circ}$ out of phase with those from the LN mechanism. 
One important feature of the SST field in the eastern equatorial Pacific is the presence of a cold tongue centered at around $1^{\circ} \mathrm{S}$, which is typically present from May up to February. Monthly period waves occur along the boundary of the cold tongue, commonly known as tropical instability waves (TIWs; see Fig. 1, e.g.). They have typical wavelengths of $1000-1300 \mathrm{~km}$, and periods of around 20-30 days (Legeckis 1977).

HMW found correlations between wind speed difference and SST difference between two locations spanning the SST front when the data were filtered to show the monthly period TIWs. Based on a phase analysis, they suggested that vertical stability was again the main factor in determining wind speed, such that trade winds were enhanced over warm SST and reduced over cold SST. An important premise for this explanation is that the SST changes are sufficiently small scale so that the air temperature does not adjust to equilibrium with the SST, and the surface layer is unstable over the warm SST and stable over cold SST.

The LN and HMW explanations differ in the relative importance they put on vertical mixing and pressure gradient. Until the late 1990s only limited in situ and satellite data were available to confirm or deny these theories. Xie et al. (1998) found some evidence to support HMW in the first satellite study of coupled TIWs but the study was limited by the weekly resolution of the European Remote Sensing Satellite (ERS) scatterometer winds, and the cloud cover problems associated with the Advanced Very High Resolution Radiometer SST.

More recently advantage has been taken of the new generation of satellites measuring the tropical oceans. On board the Tropical Rainfall Measuring Mission (TRMM) satellite, the TRMM Microwave Imager (TMI) instrument was the first to gain regular cloud-free images of SST covering most of the tropical and subtropical regions every day. The SeaWinds scatterometer on the National Aeronautics and Space Administration's Quick Scatterometer (QuikSCAT) satellite provided nearly global wind fields, also on a daily basis. Using these high-resolution data, Liu et al. (2000), Hashizume et al. (2001), and Chelton et al. (2001) studied the TIW phenomenon and noted a close correspondence between SST measured by TMI and wind speed from a scatterometer. In the cold tongue season, low wind speeds were measured over the cold water and higher speeds over the warmer surrounding waters. When the data were filtered to show anomalies due to TIWs, it was clear that the southeasterly trade winds were enhanced over the warm SST anomalies, and reduced over the colder anomalies as found by HMW and Xie et al. (1998).

Hashizume et al. (2001) and Liu et al. (2000) also investigated how the SST affected cloud liquid water and water vapor. Again using the TMI, their comprehensive data showed that nonprecipitating clouds gathered over the warm TIW anomalies or over the adjacent convergent zones of the surface winds. These vertically integrated data indicate that the effect of SST is felt throughout the atmospheric boundary layer.

So far there have been few numerical studies of PBL response to SST gradients in the equatorial cold tongue region. Xie et al. (1998) used a global general circulation model to investigate the physical processes that occur in this atmospheric response to SST driving, and found that both vertical mixing and pressure gradient terms were equally important. However the horizontal and vertical resolution of this model was rather coarse $\left(2.8^{\circ}\right.$ horizontally and four levels in the PBL), and the input SST field was idealized and fixed in time.

The purpose of this paper is to use new simulations with improved physical representations to examine why the observations show that wind speeds over TIWs are in phase with SST, and whether this really corroborates the HMW vertical mixing mechanism. To do this a new regional climate model with realistic SST input is used. The model has high resolution $\left(0.5^{\circ}\right.$ horizontally and 29 vertical levels) and improved physics in the PBL (see below).

The paper is organized as follows. The model is described in brief in section 2, together with details of the initial and boundary conditions, and a short description of the analysis methods. Section 3 presents the model simulations of PBL response to the TIWs. Section 4 goes on to describe the contributions by pressure gradient force, advection, and vertical mixing to the momentum budgets. Comparisons with observations are made wherever possible in sections 3 and 4 . Section 5 presents discussion and conclusions.

\section{The model and analysis methods}

\section{a. Model description and boundary conditions}

The atmospheric model used is the regional climate model, IPRC-RegCM, recently developed at the International Pacific Research Center, University of Hawaii. A detailed description of the IPRC-RegCM and its performance in simulating regional climate over east Asia can be found in Wang et al. (2003). The model uses hydrostatic primitive equations in spherical coordinate with sigma (pressure normalized by surface pressure) as the vertical coordinate. The model equations are solved with a fourth-order conservative finite-difference scheme on an unstaggered longitude-latitude grid system and a leapfrog scheme with intermittent use of a Euler backward scheme for time integration. The model has 29 vertical levels with substantial high resolution in the planetary boundary layer (10 levels below 800 $\mathrm{hPa}$ ). In this study the model domain extended from $25^{\circ} \mathrm{N}$ to $25^{\circ} \mathrm{S}, 90^{\circ}$ to $150^{\circ} \mathrm{W}$, with a grid spacing of $0.5^{\circ}$. The model physics include the detailed cloud microphysics scheme of Wang (2001) for grid-scale moist processes; a mass flux scheme for subgrid shallow convection, midlevel convection, and deep convection developed by Tiedtke (1989) and modified by Gregory et 
a) Observations

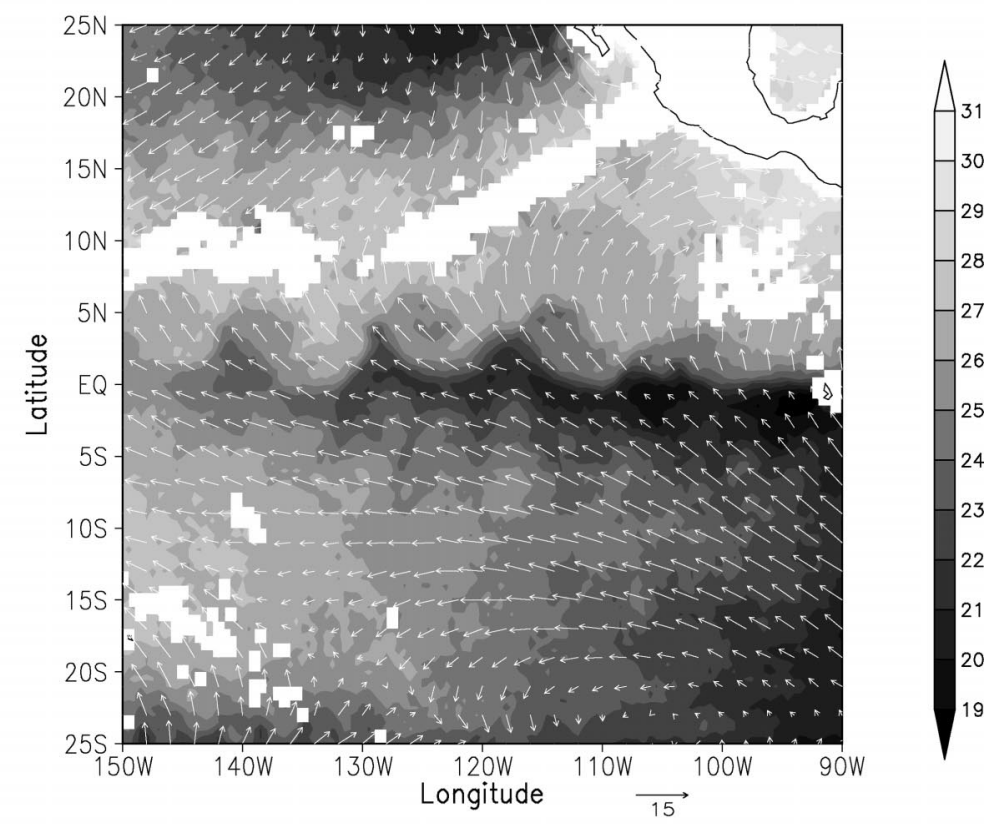

\section{b)Model}

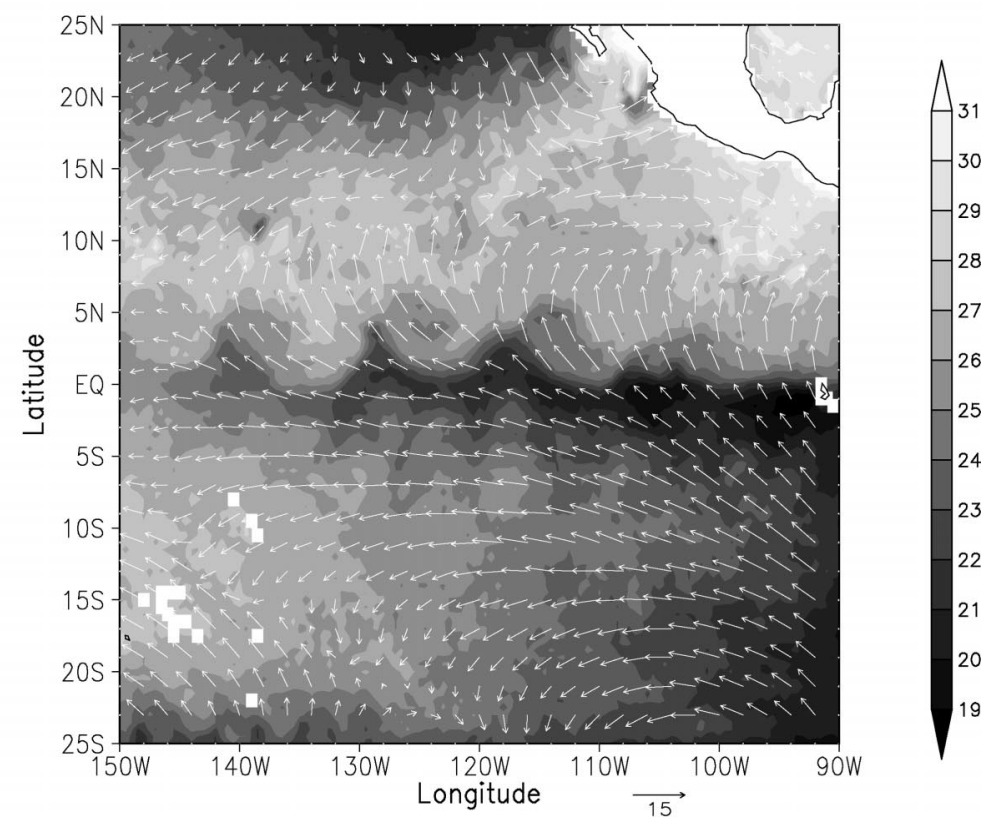

FIG. 1. SST (shading, ${ }^{\circ} \mathrm{C}$ ) and 10-m neutral equivalent wind vectors $\left(\mathrm{m} \mathrm{s}^{-1}\right.$, see scale arrow) over the model domain for a 3-day mean centered on 7 Sep 1999. (a) Observed SST from TMI and wind vectors from QuikSCAT, (b) processed SST data for simulation, with errors replaced with interpolation between good data, and modeled winds over the ocean. Data gaps are shown in white. 
al. (2000); an $E-\varepsilon$ turbulence closure scheme for vertical mixing (Langland and Liou 1996); the radiation package developed by Edwards and Slingo (1996) and further improved later by Sun and Rikus (1999); the BiosphereAtmosphere Transfer Scheme (BATS) developed by Dickinson et al. (1993) for land surface processes; and a modified Monin-Obukhov similarity scheme for flux calculations at the ocean surface (Wang 2002; Fairall et al. 1996). The bulk flux formulas are summarized in appendix A for reference.

The modified mass flux scheme uses a convective available potential energy (CAPE) closure and considers the organized entrainment/detrainment based on a simple cloud plume model (Gregory et al. 2000). The detrained cloud water/ice at the top of cumulus towers are added to the corresponding grid-scale cloud water/ice to improve the model cloudiness calculation (Wang et al. 2003). The radiation package includes seven (four) bands for longwave (shortwave) radiation calculation. We considered a full coupling between the cloud microphysics and the cloud optical depth. The cloud properties are calculated based on Sun and Shine (1994) for longwave radiation, and Slingo and Schrecker (1982) and Chou et al. (1998) for shortwave radiation. Cloud amount is diagnosed using the semiempirical cloudiness parameterization scheme developed by $\mathrm{Xu}$ and Randall (1996), by which cloud amount is determined by both relative humidity and liquid/ice water content.

\section{b. Boundary and initial conditions}

The model atmosphere responds to a prescribed timedependent SST, which in this case was a daily SST product derived from a 3-day running mean of TMI data. The SST values through the day used in the model were then obtained from linear interpolation in time. The TMI instrument has an ability to see through clouds and is limited only in regions of strong precipitation and near coasts (Wentz et al. 2000). The TMI version 2 data are provided on a $0.25^{\circ}$ grid, which is sufficient to resolve the 1000-km-long TIWs. For the simulations, the TMI data were processed by spatially interpolating over error data (caused by precipitation) and missing data (e.g., near coastline areas) using the Interactive Data Language (IDL) triangulate and trigrid routines (IDL 1995). Figure $1 \mathrm{~b}$ shows a result of such interpolation, where the original errors are mainly located in the heavy precipitation region of the intertropical convergence zone (ITCZ).

National Centers for Environmental Prediction-National Center for Atmospheric Research (NCEP-NCAR) reanalysis (Kalnay et al. 1996) version 3 products (released in May 2002) are used to initialize the model and to provide lateral boundary conditions (see Wang et al. (2003) for details). [A comparison with the model results using European Centre for Medium-Range Weather Forecasts (ECMWF) 12-hourly data as inputs did not show significant differences in the region of interest: the equatorial cold tongue.] The model was run for 2 months to simulate the period of 1 September 1999 to 31 October 1999. Note that the simulation period coincided with La Niña, which exhibited a prominent cold tongue and associated TIWs [see, e.g., Contreras (2002) for a discussion of the observed relationship of TIWs to the background ocean state].

\section{c. Analysis techniques}

TIWs tend to propagate directly westward, and have wavelengths around $9^{\circ}-13^{\circ}$ of longitude. Following Hashizume et al. (2001), the observed and modeled data have been filtered to isolate TIW effects by removing a $12^{\circ}$ running mean at each latitude. For many of the figures a linear regression analysis was performed on the filtered data. This allows identification of the relationship between a field variable and a TIW "index" such as the SST at a fixed point. Details of the regression method are described in Hashizume et al. (2001).

\section{Planetary boundary layer structure: Simulations and observations}

In this paper the model simulations will be compared with data from the QuikSCAT and TRMM satellites. The QuikSCAT scatterometer measures stress on the sea surface. The stress is not just related to background wind speed at some height above the surface but also to the static stability. However the stress is related uniquely to neutral equivalent wind at $10 \mathrm{~m}, U_{10}$ (namely the wind speed that would have occurred at $10 \mathrm{~m}$ if the surface stability was neutral, rather than its actual value), as shown in (A2). For this reason the neutral equivalent wind speed at $10 \mathrm{~m}, U_{10}$, will be used to compare the model and observed values of wind velocity near the surface. The QuikSCAT twice-daily data were averaged over a day to give more complete maps.

\section{a. Horizontal structure}

The large-scale characteristics of the surface wind field and their relationship with the underlying SST field during the TIW season are illustrated on a typical day (7 days into the simulation) in Fig. 1. In both the observations (Fig. 1a) and model (Fig. 1b), similar gross patterns are evident in the neutral equivalent wind vectors: southeasterly and easterly trades over the southern half of the domain; a reduction in the speed of the southeasterlies as they cross the cold tongue; an increase in speed and a more southerly component between $0^{\circ}$ and $10^{\circ} \mathrm{N}$; convergence into the ITCZ at around $10^{\circ} \mathrm{N}$ over warm water; westerly winds close to the North American coast at the same latitude over the warmest SST; and northerly and northeasterly winds to the north on the edge of the subtropical high over relatively cooler SST.

The effect of the transient TIWs on the wind speed 
a) Obs. SST and $U_{10}$
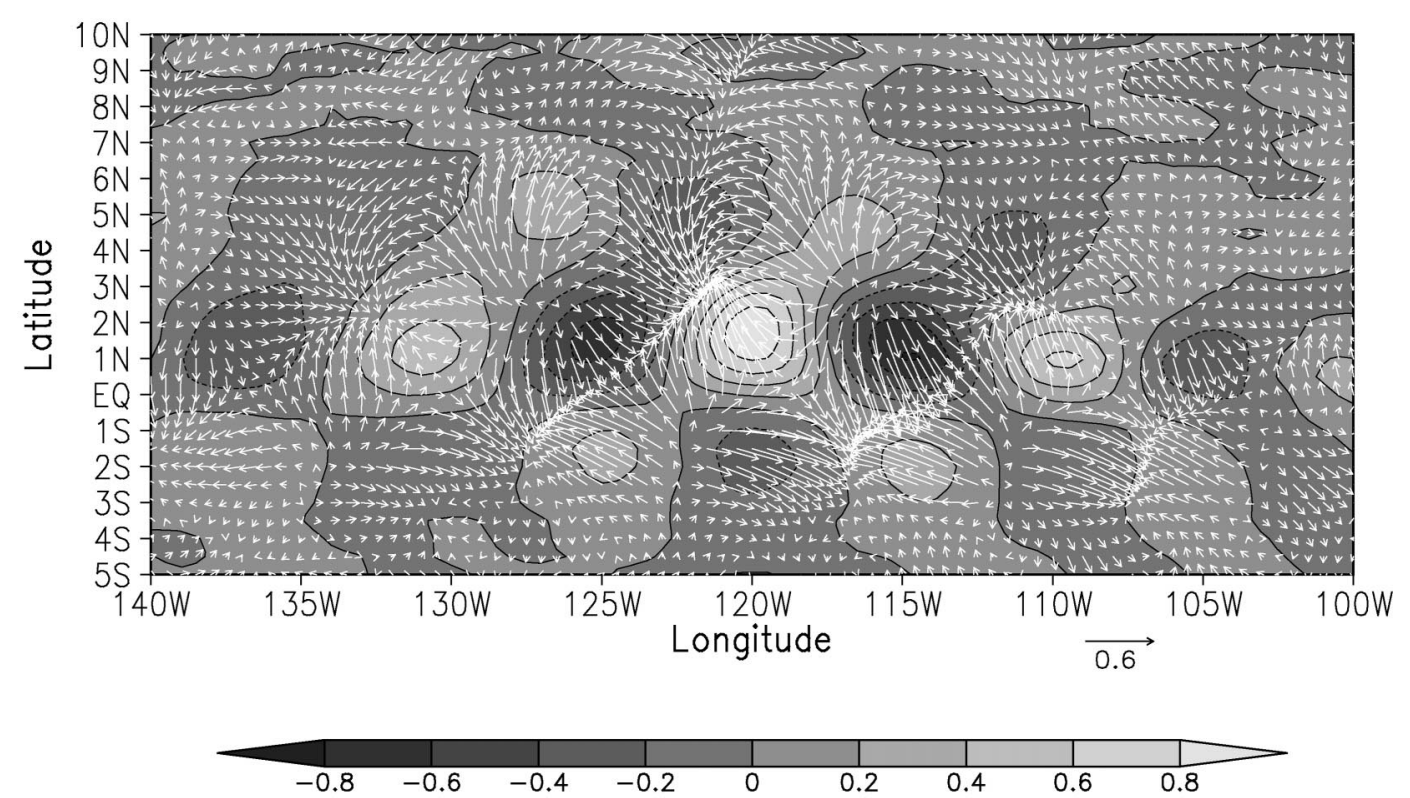

b) Model SST and $U_{10}$
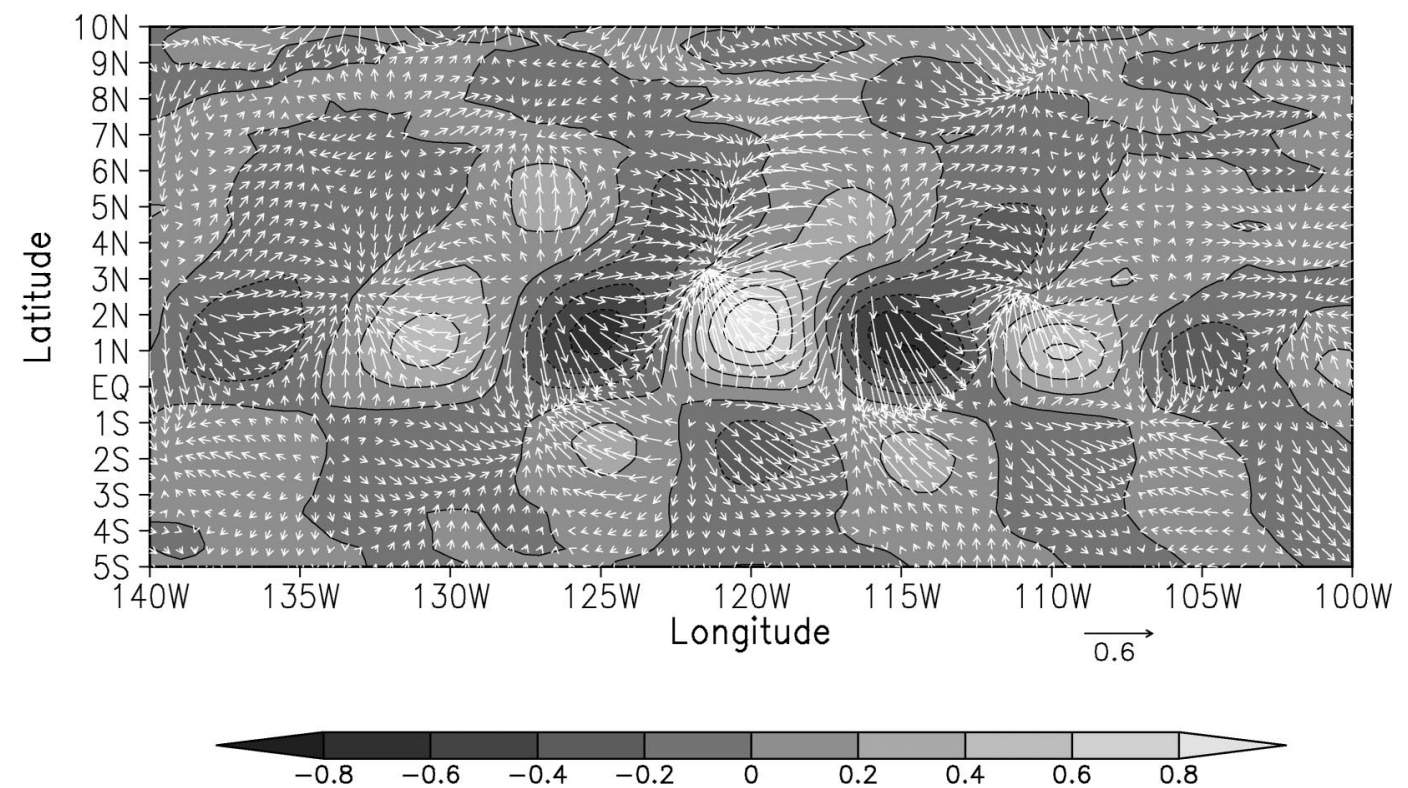

FIG. 2. Regression coefficients of TIW anomalies for a center point at $2^{\circ} \mathrm{N}, 120^{\circ} \mathrm{W}$ SST (shading) and 10 -m neutral equivalent winds (vectors, $\mathrm{m} \mathrm{s}^{-1} \mathrm{~K}^{-1}$ ). (a) Observations from TMI and QuiKSCAT. (b) Model simulation.

is seen more clearly by performing the filtering and regression described in section $2 \mathrm{c}$. The reference point chosen was $2^{\circ} \mathrm{N}, 120^{\circ} \mathrm{W}$, in the latitudinal band of TIW variability and where the SST time series showed a clear signal (see appendix B, Fig. B1a).

Figure 2a shows the characteristic patterns of regressed SST and $U_{10}$ vectors identified by Liu et al. (2000) and Hashizume et al. (2001). The typical TIW wavelength $\left(9^{\circ}-13^{\circ}\right.$ longitude $)$ is clear in the SST regression as well as the eastward tilt with increasing latitude. The SST anomalies are antisymmetric about the equator, but the southern anomalies are much weaker. The near-surface wind anomalies act to strengthen the southeasterly trades over warm SST and weaken the trades over cold SST with a magnitude of up to \pm 0.6 $\mathrm{m} \mathrm{s}^{-1} \mathrm{~K}^{-1}$ (see Fig. 3a for a close-up). Convergence lines are apparent west of the warm SST anomalies, and divergence west of the cold anomalies. Two interesting features confirm what was found in Hashizume et al. (2001): although the SST anomalies disappear north of 
a)

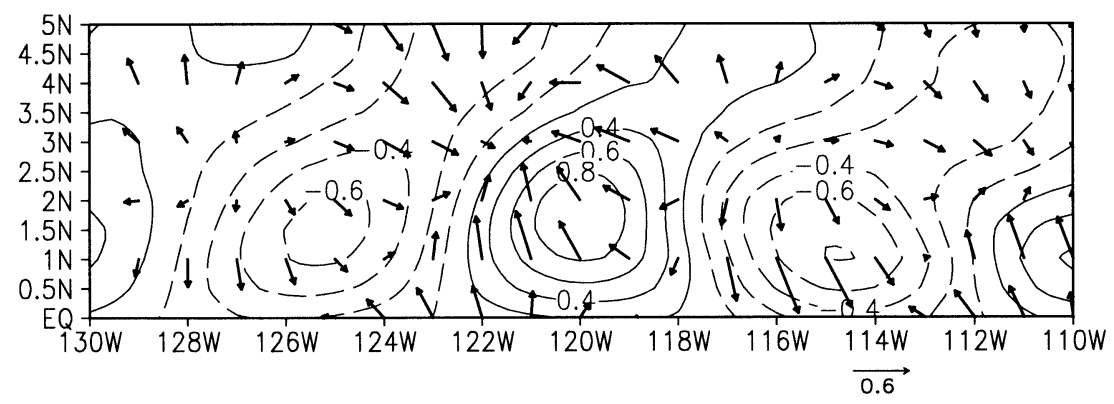

b)

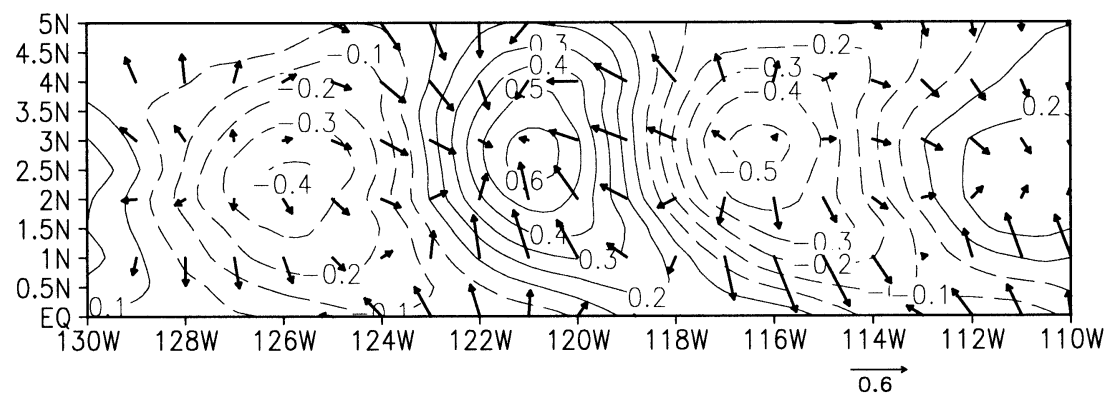

c)

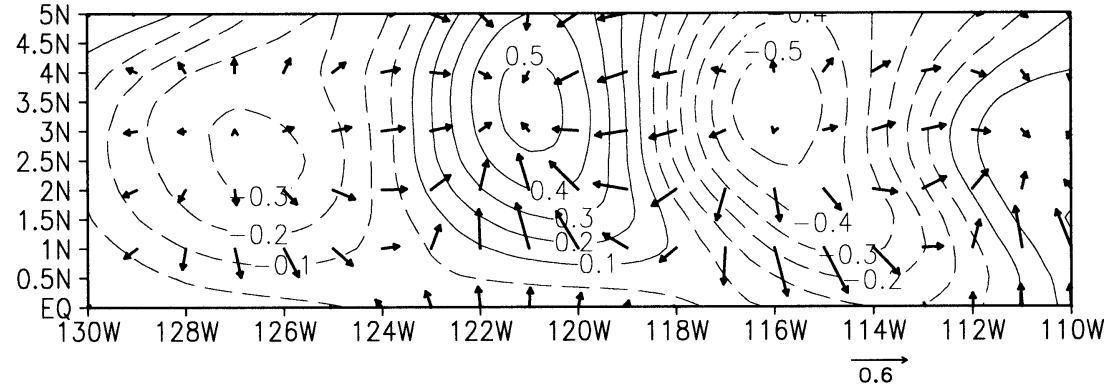

FIG. 3. Close-up of distribution of regression coefficients between $0^{\circ}$ and $5^{\circ} \mathrm{N}, 130^{\circ}$ and $110^{\circ} \mathrm{W}$. (a) Observed SST (contours) and 10-m neutral equivalent wind vectors $\left(\mathrm{m} \mathrm{s}^{-1} \mathrm{~K}^{-1}\right)$, from TMI and QuikSCAT. (b) Observed column-integrated water vapor (contours, $\mathrm{mm} \mathrm{K}^{-1}$ ) and 10 -m neutral equivalent wind vectors $\left(\mathrm{m} \mathrm{s}^{-1} \mathrm{~K}^{-1}\right)$, from TMI and QuikSCAT. (c) Model column-integrated water vapor (contours, $\mathrm{mm} \mathrm{K}^{-1}$ ) and $10-\mathrm{m}$ neutral equivalent wind vectors $\left(\mathrm{m} \mathrm{s}^{-1} \mathrm{~K}^{-1}\right)$.

$6^{\circ} \mathrm{N}$ there are still wind anomalies even at the northern edge of the plot at $10^{\circ} \mathrm{N}$, suggesting a link of TIWs with the ITCZ, and wind anomalies in the Southern Hemisphere can be quite large even though the SST anomalies are small.

For comparison Fig. 2b shows the model-simulated $U_{10}$ regression vectors over the SST. Many of the features of the model vector field are similar to the observations, including the stronger trade winds over the warm SST, weaker trades over the cold SST, and the location of the convergence lines and the divergence. The model also shows wind perturbations at the northern edge of the plot. However the wind response appears to be weaker in the Southern Hemisphere in the model than in the observations. Over the main TIW distur- bances in the center of the plot the wind velocities are similar in observation and model as shown in more detail in Fig. 3.

As the mean wind direction in this region is southeasterly (see Fig. 1), Fig. 2 also indicates that the magnitude of $U_{10}$ and hence of the wind stress [see (A2)] is increased over warm water and decreased over cold SST. The increase in stress over warm water may be due to changes in static stability and also due to variations in wind speed above the constant flux layer. The relative importance of these two factors has been investigated in a simple surface-layer experiment in appendix $\mathrm{B}$, which indicates that static stability has a secondary effect on surface stress variations compared to that due to the higher-level wind fluctuations. The cause 
a)

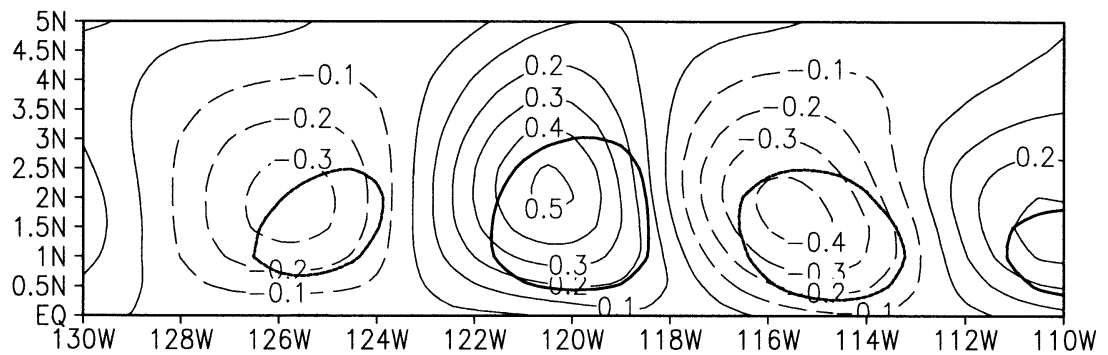

b)

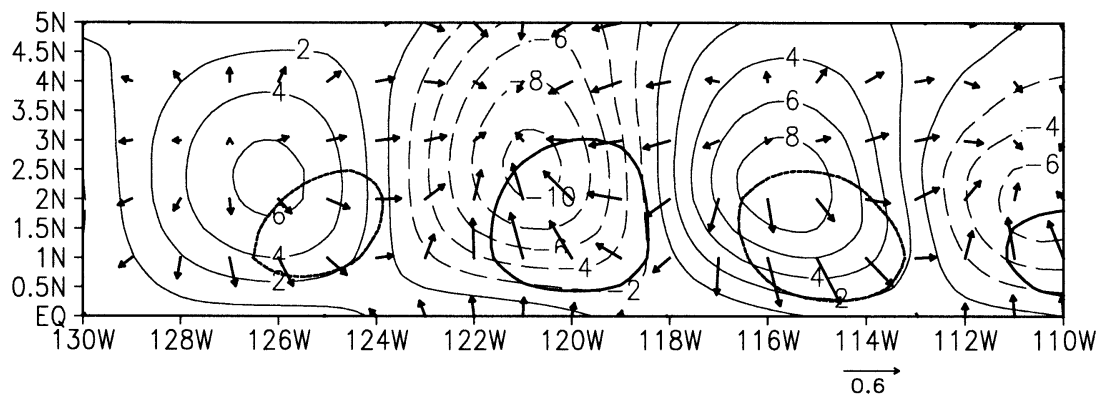

FIG. 4. Close-up of distribution of regression coefficients between $0^{\circ}$ and $5^{\circ} \mathrm{N}, 130^{\circ}$ and $110^{\circ}$ $\mathrm{W}$, model results. (a) Air temperature (at lowest model level, line contours), and SST (thick line contours at + and -0.5 ). (b) Surface pressure (line contours, $\mathrm{Pa} \mathrm{K}^{-1}$ ), SST (thick line contour at + and $-0.5 \mathrm{~K})$, and surface wind vectors $\left(\mathrm{m} \mathrm{s}^{-1} \mathrm{~K}^{-1}\right)$.

of these fluctuations in higher-level wind is discussed below.

As the largest regression values in Fig. 2 are concentrated in the region north of the equator $\left(0^{\circ}-5^{\circ} \mathrm{N}\right)$ and for $130^{\circ}-110^{\circ} \mathrm{W}$, this area will be used to discuss the relationship between the model variables. For reference, Fig. 3a shows the observed SST and $U_{10}$ regression in the region.

The column-integrated water vapor (CIWV) gives an indication of the effect of TIWs on the whole of the PBL. Figures 3b,c show observation and model intercomparisons of CIWV and $U_{10}$ vectors. The extrema of CIWV are located slightly northward and westward (downstream) of the SST extrema. This displacement is about $1^{\circ}$ westward in both the observation (Fig. 3b) and model (Fig. $3 \mathrm{c}$ ), and $1^{\circ}\left(2^{\circ}\right)$ northward in the observation (model), respectively. The magnitude of the CIWV extrema are similar in the observations $\left(-0.5 \mathrm{~mm} \mathrm{~K}^{-1}\right.$ : $\left.+0.6 \mathrm{~mm} \mathrm{~K}^{-1}\right)$ and the model $\left(-0.5 \mathrm{~mm} \mathrm{~K}^{-1}\right.$ : +0.5 $\mathrm{mm} \mathrm{K} \mathrm{K}^{-1}$ ). In both the observation and model the CIWV maxima and minima correspond closely with regions of wind convergence and divergence, respectively.

The model also allows inspection of other variables that are not observed by satellite. The near-surface air temperature regressions (Fig. 4a) exhibit extrema, which, like the CIWV, are located slightly downstream of the SST extrema (the + and -0.5 contours of SST are overlaid on Figs. $4 a, b$ as thick contours for comparison) and reach values of -0.5 and +0.5 , with a discernibly larger meridional scale than SST (i.e., the air temperature perturbation decreases to the north to half its maximum perturbation from $2^{\circ}$ to $4^{\circ} \mathrm{N}$ in Fig. $4 \mathrm{a}$, while the SST decreases by half from $2^{\circ}$ to $3^{\circ} \mathrm{N}$ in Fig. 3a).

Figure $4 \mathrm{~b}$ shows that the anomalous wind field is similar to that expected from pressure gradient driven flow, as one might expect given the small Coriolis parameter at these latitudes. In fact, the more detailed analysis of the momentum budget in section $4 \mathrm{~b}$ indicates that not just pressure gradient, but vertical mixing and horizontal advection are all important to the wind field. The magnitude of the pressure anomaly reaches -10 $\mathrm{Pa} \mathrm{K}^{-1}\left(0.1 \mathrm{mb} \mathrm{K}^{-1}\right)$ and $+8 \mathrm{~Pa} \mathrm{~K}^{-1}\left(0.08 \mathrm{mb} \mathrm{K}^{-1}\right)$. It is interesting to note that the high and low pressures do not sit over low and high SST, respectively, but in the SST gradient regions in between. The reason for this is that the air density is inversely related to virtual temperature $T_{v}\left(T_{v}=T_{a}+0.61 q\right.$, where $q$ is the specific humidity) via the ideal gas law, so that the hydrostatic surface pressure minimum is located between the $T_{a}$ and $q$ maxima. As $T_{a}$ and CIWV maxima are located downstream of the SST maxima (Figs. 4a, 3c), and the CIWV represents the typical location of centers of $q$ in the vertical, the pressure minimum is also located downstream. (Also, the $T$ anomaly slopes more downstream with increasing height in the model, so that the vertical integral used for hydrostatic balance is again shifted toward downstream). Hence the winds that diverge from pressure maxima and converge into pressure minima have the highest magnitude over the SST maximum. 
a)
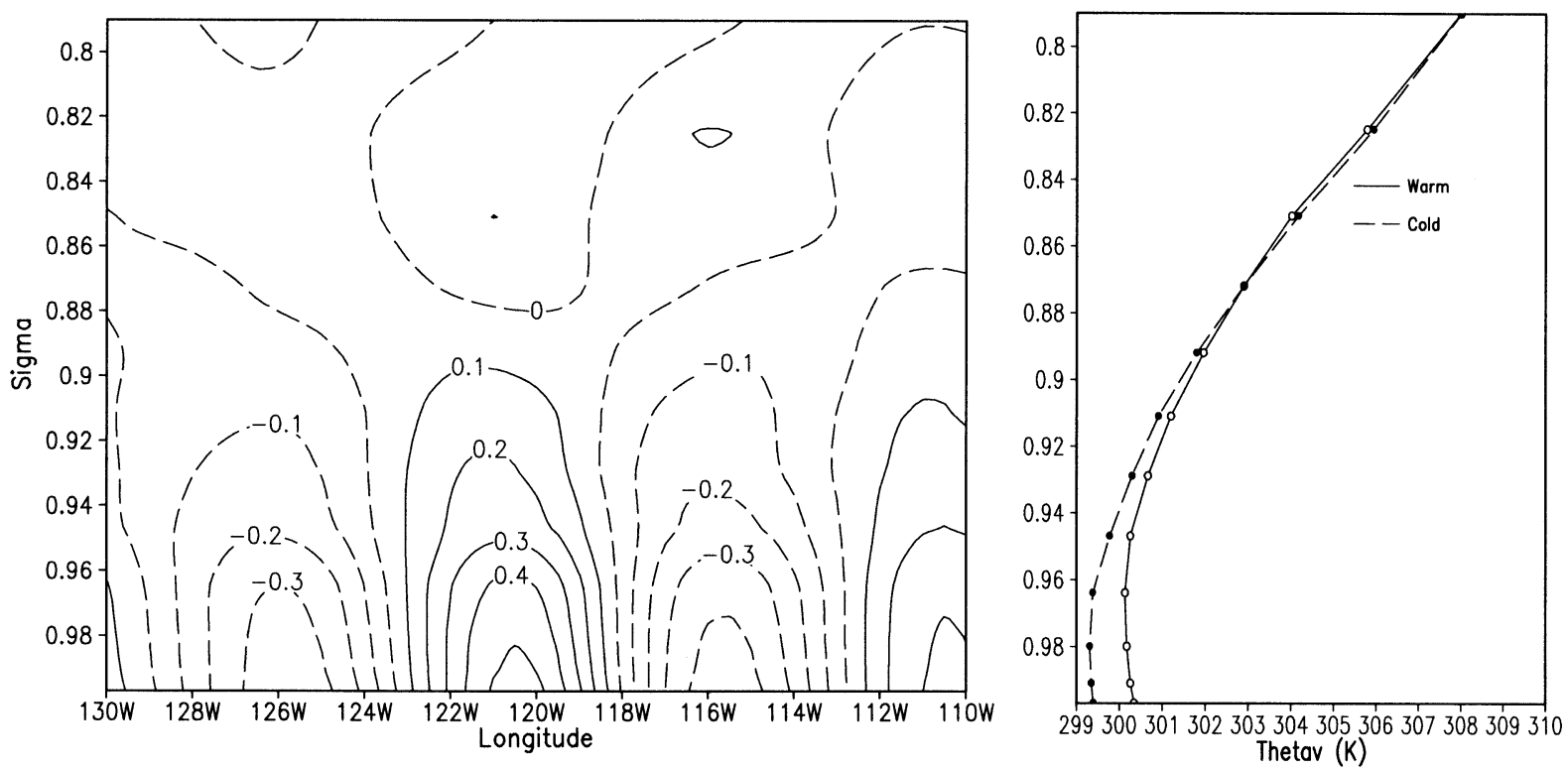

b)
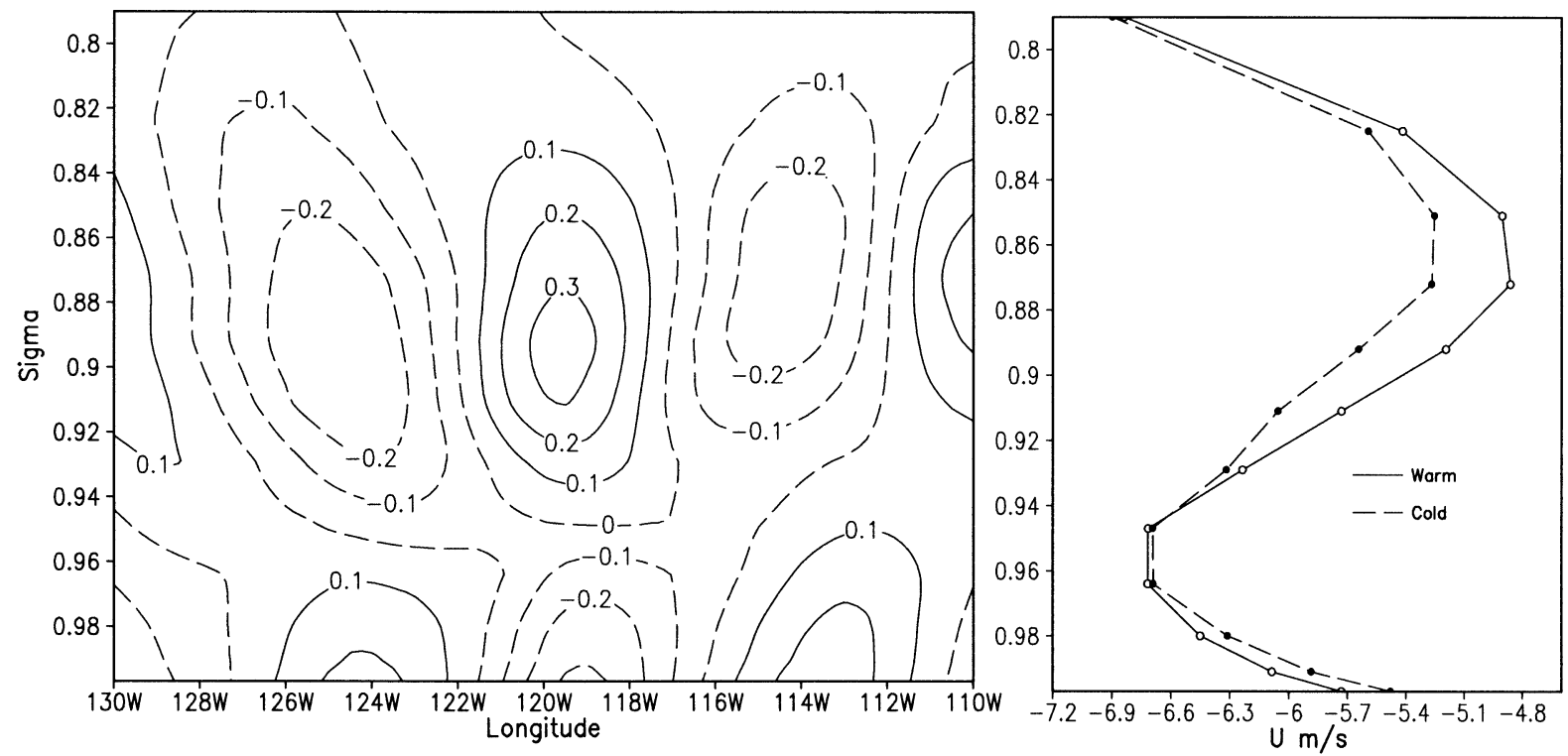

FIG. 5. (left) Regression coefficients (per unit K) in a longitude-vertical plane at $2^{\circ} \mathrm{N}$. The vertical coordinate is $\sigma$, and ranges from the surface to about $2 \mathrm{~km}$ height. (right) Accompanying total profiles over warm SST (solid line with unfilled symbols) and over cold SST (dashed line with filled symbols). (a) Virtual potential temperature (K), (b) $U$ velocity $\left(\mathrm{m} \mathrm{s}^{-1}\right.$ ), (c) $V$ velocity (m s${ }^{-1}$ ), (d) specific humidity $\mathrm{g} \mathrm{kg}^{-1}$ with vectors of $(u, w \times 100),\left(\mathrm{m} \mathrm{s}^{-1}\right)$ overlain.

There is some evidence from in situ observations that the model relationships of the surface pressure and the near-surface air temperature to the SST are realistic. Cronin et al. (2003) studied a 21-month series of nearsurface pressure, SST, and air temperature measurements from the Tropical Atmosphere Ocean (TAO) array at $\left(110^{\circ} \mathrm{W}, 2^{\circ} \mathrm{S}, 0^{\circ} \mathrm{N}, 2^{\circ} \mathrm{N}\right)$. They found transfer coeffi- cients of $0.16 \mathrm{mb} \mathrm{K}^{-1}$ (comparable with the model values discussed earlier) and noted that the pressure anomalies led the SST anomalies by up to 4 days (i.e., low pressure occurred 4 days before high SST). Further, pressure and air temperature anomalies were more in phase than pressure and SST. These observations are reasonably consistent with the model simulations. 
c)
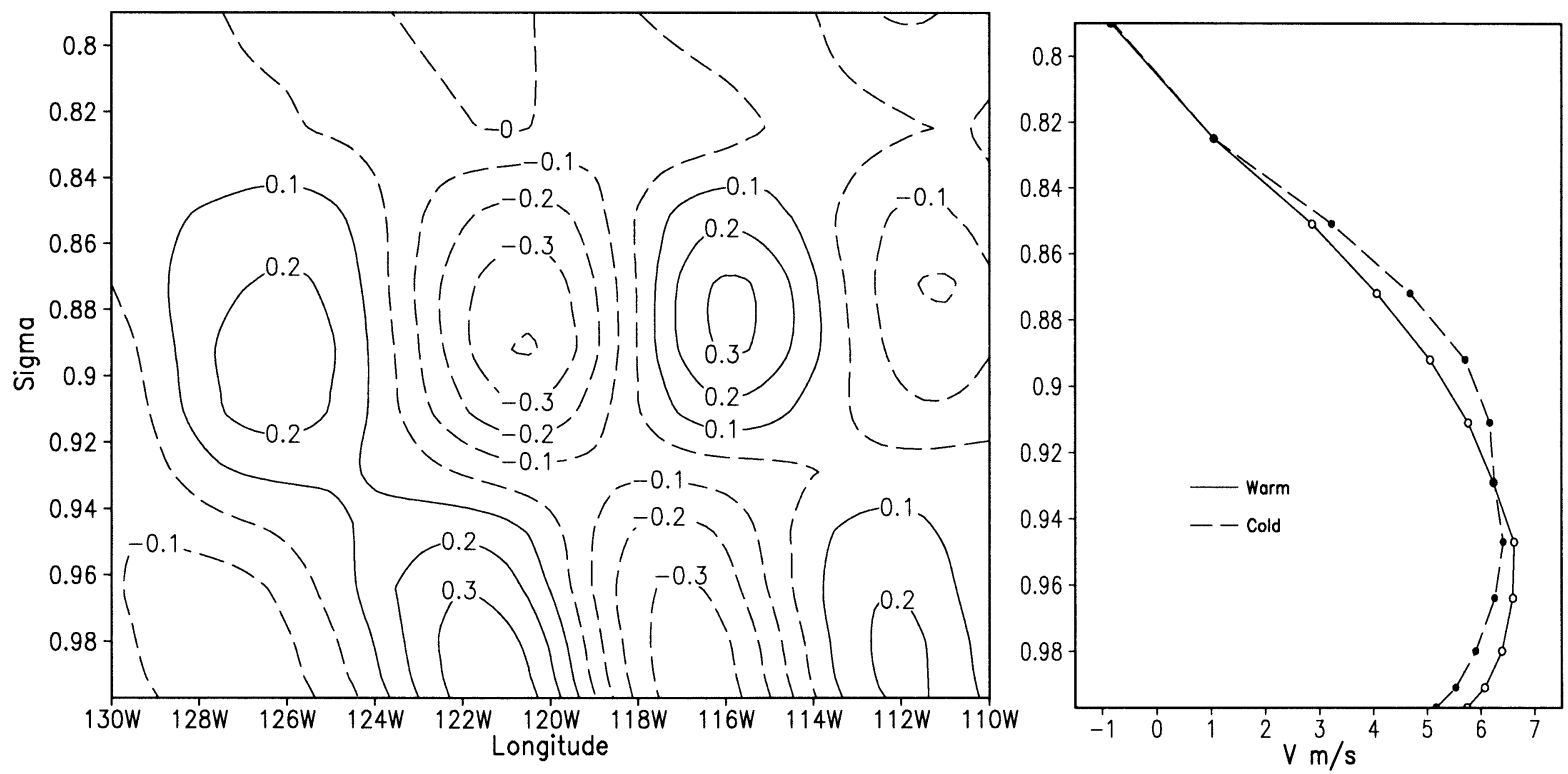

d)
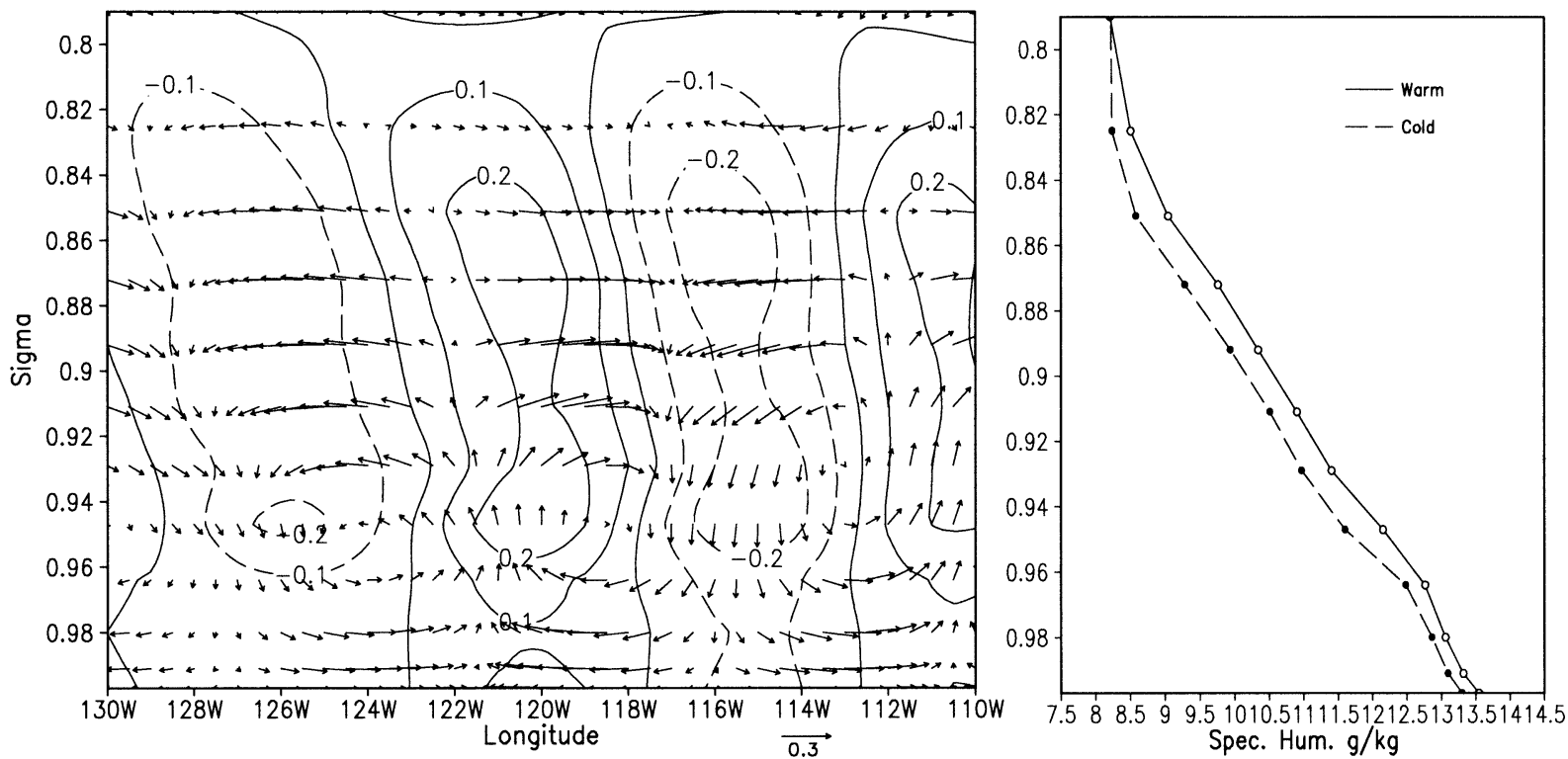

FIG. 5. (Continued)

\section{b. Vertical structure}

Vertical structures of the TIW regression coefficients in a latitudinal plane at $2^{\circ} \mathrm{N}$ are shown in Fig. 5 (left) together with representative model profiles over warm SST and cold SST (Fig. 5, right). The warm and cold profiles were obtained by taking the time mean profile at $2^{\circ} \mathrm{N}, 120^{\circ} \mathrm{W}$, and adding on the regressed profile at a position of large positive $S S T$ regression at $2^{\circ} \mathrm{N}\left(121^{\circ} \mathrm{W}\right.$ : $\mathrm{SST}$ regression $=0.73$ ) and at the position of large negative SST regression at $2^{\circ} \mathrm{N}\left(115^{\circ} \mathrm{W}\right.$ : SST regression $=-0.72)$, respectively.

The virtual potential temperature $\left(\theta_{v}\right)$ perturbations (Fig. 5a) are confined mainly to the boundary layer and correspond to sensible heating from the warming/cooling of SST (compare with the surface distribution of SST regression at $2^{\circ} \mathrm{N}$, Fig. 5a) but with a weak reversal of sign $\left(\theta_{v}\right.$ perturbation magnitude less than 0.1$)$ above $\sigma=0.88$. The corresponding plot for virtual air temperature $\left(T_{v}\right.$, not shown) shows that the reversal of sign 
reaches a magnitude of just over 0.1 . The corresponding warm and cold profiles of $\theta_{v}$ show over warm SST a mixed, slightly unstable layer exists to around $400 \mathrm{~m}$, compared to a 200-m mixed layer over cold SST. The PBL is slightly more stably stratified in the cold SST case.

As discussed earlier the rate of change of hydrostatic pressure with height is inversely related to $T_{v}$ and so it should be noted that anomalies of pressure will reverse sign below $\sigma=0.88$. This sets up a thermally direct circulation cell affecting the wind velocities and water vapor. The consequences of this are discussed in the following.

The vertical structure of the regression coefficients of $U$ can be seen in Fig. 5b. A negative surface coefficient of $U$ lies over and to the east of warm SST. Above $\sigma$ $=0.95$ (about 500-m height) this anomaly changes sign. As seen in the profiles in Fig. 5b this leads to an increase of easterly wind at the surface, and a decrease in the easterly flow above $500 \mathrm{~m}$ (at around 300-500 m there is a maximum of easterly flow in the model results), above the warm SST. Over cold SST this effect is reversed: the easterly wind at the surface is reduced, and stronger easterly flow is at higher levels between 500 and $1000 \mathrm{~m}$ (Fig. 5b).

Anomaly dipoles also exist in the $V$ velocity regressions (Fig. 5c). To the west (up to $90^{\circ}$ phase shift) of the warm SST and $\theta_{v}$, positive $V$ regression coefficients at the surface indicate an enhancement of the southeasterly trades there, while above $500 \mathrm{~m}$ the flow is weakened. Over the cold SST the reverse occurs. Some indication of this effect is seen in the profiles of Fig. 5c. (As the $V$ regression anomalies are phase-shifted relative to SST anomalies the compositing fails to capture the maximum contrast.)

Water vapor regression coefficients are nearly in phase with the SST and $\theta_{v}$, anomalies (Fig. 5d), but show a westward tilt with height that contributes to the vertically integrated quantity being shifted in phase westward of the SST. The largest water vapor anomalies lie between 500 and $1500 \mathrm{~m},(\sigma=0.95-0.85)$ with local maxima at the top and bottom of this vertical range.

The convergence and pressure fields shown in Fig. $4 \mathrm{~b}$ set up a thermally direct circulation cell. The anomalous circulation in the vertical plane at $2^{\circ} \mathrm{N}$ is also indicated in Fig. 5d (left), with the vertical component of the velocity ${ }^{1}$ increased 100 -fold (so that the vectors are appropriate for the aspect ratio of the plot). Circulation cells can be seen with ascent over surface convergence coinciding with high water vapor (WV) anomalies, and descent over surface divergence where the low WV are located. There is a return flow aloft at around $\sigma=0.9$. Vertical velocity extrema are centered

\footnotetext{
${ }^{1}$ Vertical velocity $w$ has been derived from the sigma coordinate velocity $\omega=d p / d t$ by the approximate relationship for synoptic scales derived from hydrostatic balance (Holton 1992, section 3.5), $\omega=$ $-\rho g w$.
}

on $\sigma=0.94$ and located slightly to the west (downstream) of SST extrema. Peak vertical velocities are around + and $-0.012 \mathrm{~m} \mathrm{~s}^{-1} \mathrm{~K}^{-1}$.

From Fig. $5 \mathrm{~d}$ it can be seen that the water vapor anomalies extend higher than the circulation cell. It is possible that this is due to mixing within clouds (cloud liquid water is also high at these levels, not shown here) of water vapor entrained from the lowest $1 \mathrm{~km}$. Another possibility is that high cloud liquid water values to the north (i.e., toward the ITCZ) have been transported southward by the anomalous meridional velocity ( $V$ is negative over the high water vapor anomalies, compare Figs. 5c, 5d).

In order to help discern the relationship of the TIW perturbations to turbulent effects, the regression coefficients and composite profiles of vertical mixing coefficient $K_{m}$ are shown in Fig. 6. Over warm SST there is an increase in $K_{m}$ of $4 \mathrm{~m}^{2} \mathrm{~s}^{-1} \mathrm{~K}^{-1}$, and corresponding negative perturbations of $-4 \mathrm{~m}^{2} \mathrm{~s}^{-1} \mathrm{~K}^{-1}$ occur over cold SST. The composite profiles of $K_{m}$ show how the maximum mixing coefficient changes from 7 to $14 \mathrm{~m}^{2}$ $\mathrm{s}^{-1}$ between cold and warm SST.

There are two main reasons for the large differences in mixing coefficient between warm and cold SST. First, at the surface the turbulent kinetic energy (TKE) is proportional to the square of the wind friction velocity (Detering and Etling 1985), which increases in warm SST and decreases in cold SST. The high TKE at the surface then influence the interior values through the vertical transport of TKE by turbulent eddies. Second, TKE is also influenced by the background source terms. Analysis of the source terms for the TKE equation showed that the stability term is dominant in the region of $\sigma=$ $0.94-1.0$, so that TKE is high over warm water and weaker stratification, and low over the cold water and stable stratification. Between $\sigma=0.88-0.94$ the stability and shear source terms have roughly similar magnitude but opposite sign, and hence the effect on TKE there is smaller. Consequently the TKE anomalies have the largest magnitude between $\sigma=0.94-1.0$, and as the dissipation rate decays roughly exponentially away from the surface (Detering and Etling 1985), the mixing coefficient is largest toward the lower end of those sigma values, at around $\sigma=0.96$ (Fig. 6).

\section{Turbulent fluxes and the momentum budget}

To understand how the vertical mixing processes in the model affect the profiles of momentum and virtual potential temperature, it is important to examine the distribution of turbulent fluxes in the horizontal and vertical, and then to relate this to the other terms in the budget equations, as described next.

\section{a. Turbulent fluxes}

The turbulent fluxes within the PBL are represented as follows, in Cartesian coordinates: 

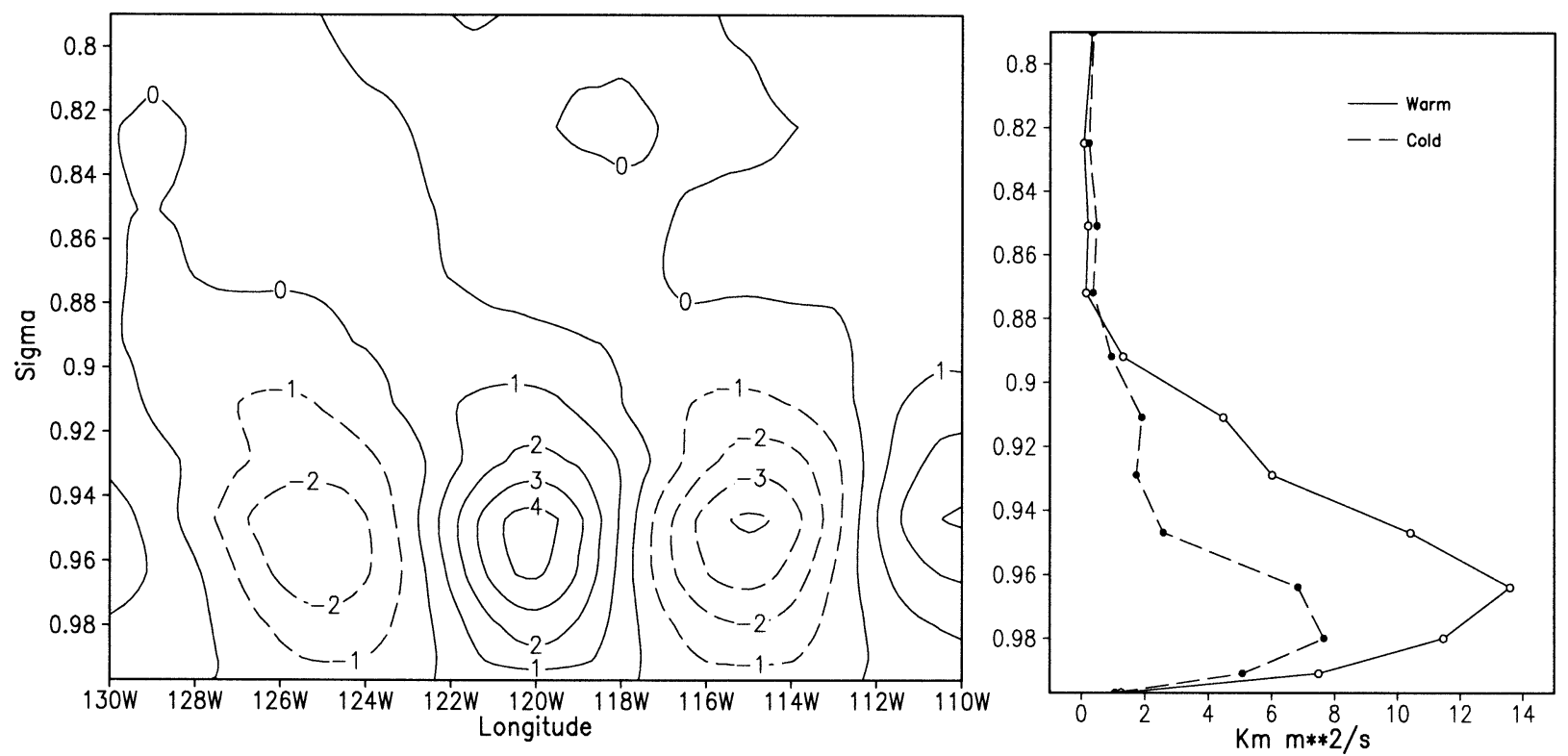

FIG. 6. As in Fig. 5, but for vertical mixing coefficient $K_{m}$ (line contours, $\mathrm{m}^{2} \mathrm{~s}^{-1}$ ).

$$
\begin{aligned}
\mathrm{UF} & =\rho \overline{u^{\prime} w^{\prime}}=-\rho K_{m} \frac{\partial u}{\partial z} \\
\mathrm{VF} & =\rho \overline{v^{\prime} w^{\prime}}=-\rho K_{m} \frac{\partial v}{\partial z} \\
\mathrm{LF} & =\rho L_{v} \overline{q^{\prime} w^{\prime}}=-\rho L_{v} K_{h} \frac{\partial q}{\partial z} \\
\mathrm{SF} & =\Pi \rho c_{p} \overline{\theta^{\prime} w^{\prime}}=-\Pi \rho c_{p} K_{h} \frac{\partial \theta}{\partial z} \\
& =-\rho c_{p} K_{h}\left(\frac{\partial T}{\partial z}+\Gamma\right) .
\end{aligned}
$$

These are the fluxes of UF: $u$ momentum, VF: $v$ momentum, LF: latent heat, and SF: sensible heat. The convention here is that positive heat flux denotes heat given from the ocean to the atmosphere. Here, $c_{p}$ is the specific heat capacity of air at constant pressure, $\theta$ is the potential temperature, $\Pi=\left(p / p_{s}\right)^{R / c_{p}}$ is the factor relating $\theta$ to $T, R$ is the ideal gas constant, $L_{v}$ is the latent heat of vaporization, $K_{m}$ is the vertical mixing coefficient of momentum, $K_{H}$ is the diffusion coefficient for heat and moisture, and $\Gamma$ is the dry adiabatic lapse rate in the atmosphere. Note that the flux terms are derived from the unfiltered background fields of $u, v$, $q, T, K_{m}$, and $K_{H}$ and hence include the effects of background shear. Then the analysis of section $2 \mathrm{c}$ is applied to the flux fields to obtain filtered and regressed quantities.

At the ocean surface the corresponding fluxes quantities UF $\left.\right|_{\text {surf }},\left.\mathrm{VF}\right|_{\text {surf }},\left.\mathrm{LF}\right|_{\text {surf }}$, and SF $\left.\right|_{\text {surf }}$ are found from the bulk aerodynamic formulas [(A1), (A2)] and sub- jected to the same filtering and regression. The distribution of the regression coefficients of the surface quantities SF $\left.\right|_{\text {surf }}$ and LF $\left.\right|_{\text {surf }}$ (Figs. 7a,b) shows that the fluxes follow a similar pattern to that of the SST regression (overlaid in Fig. 7 as thick contour lines at $\pm 0.5 \mathrm{~K}$ ). The sensible and latent heat flux regressions peaks are almost collocated at this surface level. The latent heat flux reaches larger magnitudes of up to $35 \mathrm{~W} \mathrm{~m}^{-2} \mathrm{~K}^{-1}$ (Fig. 7b) in contrast to the sensible heat fluxes of up to $6 \mathrm{~W} \mathrm{~m}^{-2} \mathrm{~K}^{-1}$ (Fig. 7a).

These patterns are comparable to observations of fluxes presented in Thum et al. (2002). They found sensible heat perturbations of about $4 \mathrm{~W} \mathrm{~m}^{-2} \mathrm{~K}^{-1}$ and latent heat perturbations of around $33 \mathrm{~W} \mathrm{~m}^{-2} \mathrm{~K}^{-1}$ at $2^{\circ} \mathrm{N}$, derived from two TIW seasons. (These values were inferred from their Fig. 8, which shows sensible heat changing by $6 \mathrm{~W} \mathrm{~m}^{-2}$ over SST change of $1.5 \mathrm{~K}$, and latent heat by $50 \mathrm{~W} \mathrm{~m}^{-2}$ over $1.5 \mathrm{~K}$, at $2^{\circ} \mathrm{N}$.) Interestingly, Thum et al. also found an eastward phase shift of sensible heat with respect to SST, by about $45^{\circ}-90^{\circ}$ of phase at $5^{\circ} \mathrm{N}$, and up to $45^{\circ}$ at $2^{\circ} \mathrm{N}$. Latent heat was also found to be phase-shifted at $5^{\circ} \mathrm{N}$, but not at $2^{\circ} \mathrm{N}$ (Thum et al. 2002). The present model results (Fig. 7a) also show evidence of a small phase shift of sensible heat eastward (by about $0.5^{\circ}$ longitude, $\sim 18^{\circ}$ of phase) at $2^{\circ} \mathrm{N}$. The eastward phase shift may be due to the fact that the air temperature maximum is north and west of the SST maximum (Fig. 4a) so that the maximum in $T_{s}$ $-T_{a}$ is actually shifted to the south and east of the SST maximum.

Superimposed on the sensible heat flux in Figs. 7a,b are vectors of the turbulent momentum flux (UF, VF) at the lowest model level. Over the high positive heat fluxes there is northwesterly momentum flux. Over the 
a)

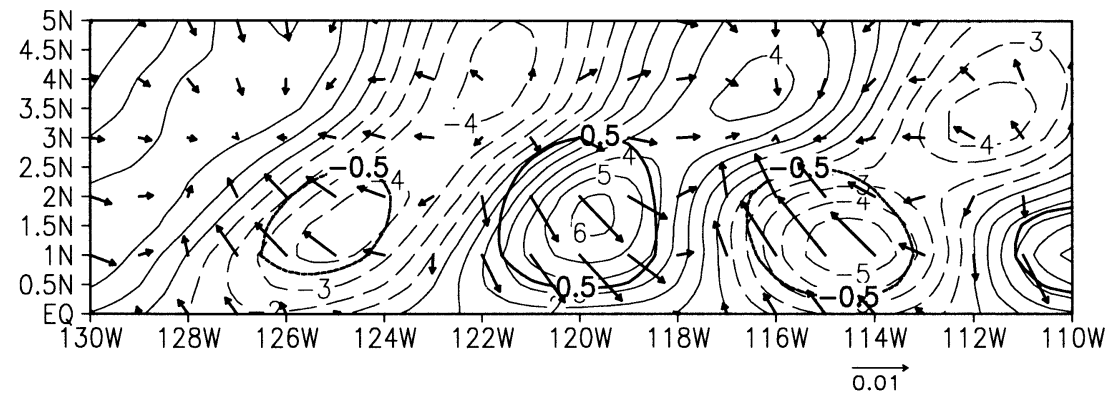

b)

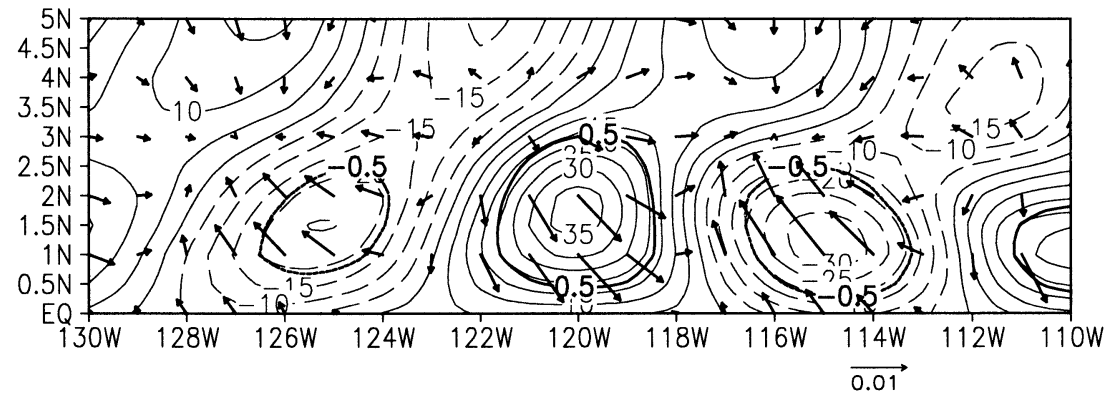

c)

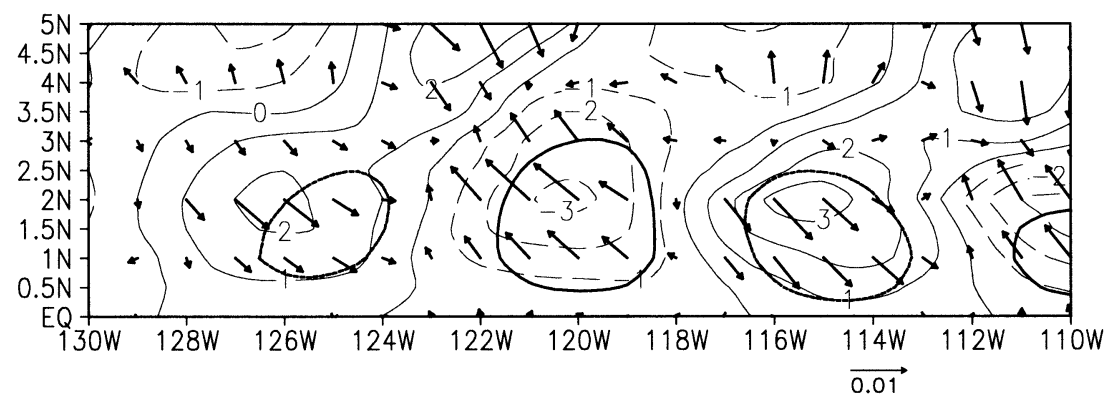

d)

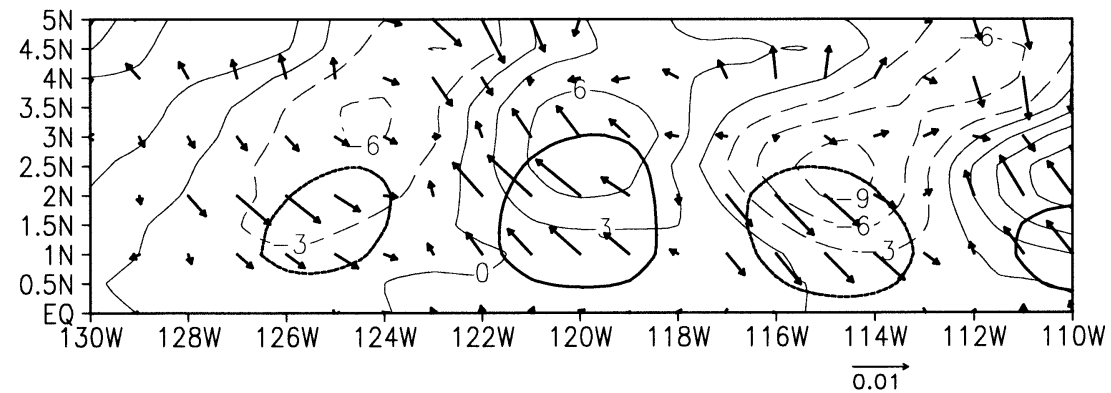

FIG. 7. Regression coefficients of turbulent flux quantities. For reference the SST regression contours of $+0.5,-0.5$ are shown as thick black contours. (a), (c) Sensible heat flux SF (line contour, $\mathrm{W} \mathrm{m} \mathrm{m}^{-2} \mathrm{~K}^{-1}$ ), and vectors of momentum flux (UF, VF) $\mathrm{m}^{2} \mathrm{~s}^{-2} \mathrm{~K}^{-1}$. (b), (d) Latent heat flux LF (line contours, $\mathrm{W} \mathrm{m}^{-2} \mathrm{~K}^{-1}$ ), and vectors of momentum flux (UF, VF) $\mathrm{m}^{2} \mathrm{~s}^{-2} \mathrm{~K}^{-1}$. (a), (b) At the surface, (c), (d) at $\sigma=0.929$ ( 700 m height).

negative heat fluxes the turbulent momentum vectors are southeasterly.

Higher in the PBL $(\sigma=0.929 \sim 700 \mathrm{~m}$ height $)$ the sensible heat flux changes sign and the SF minimum is now west and slightly north of the SST maximum (Fig. 7c). The latent heat flux extrema have shifted slightly northward by about a degree of latitude and have reduced in magnitude (Fig. 7d). The vectors of turbulent 
momentum flux have reversed direction (Figs. 7c,d) from what was seen at the lower level (Figs. 7a,b). The consequences of this are discussed in the following.

Vertical sections of the turbulent flux regressions (not shown) confirm a smoothly changing dipole structure in the vertical of SF, UF, and VF, with extrema at the surface and at around $\sigma=0.93$ and nodes around $\sigma=$ 0.97 . The latent heat flux reduces with height but remains positive. The flux perturbations are confined to below $\sigma=0.9$, confirming the height of the PBL to be around $1000 \mathrm{~m}$.

The surface and vertical distribution of the turbulent fluxes has an important effect on the resolved model variables. The mechanism of these effects is discussed next.

\section{b. The momentum budget}

The effect of the turbulent fluxes on the horizontal velocity can be determined from a detailed examination of the momentum budget. The different terms of the momentum equation were output every $6 \mathrm{~h}$ and then subjected to the same filtering and regression as performed on the prognostic variables. The momentum equation in Cartesian and vector form for $\mathbf{u}=(u, v)$ may be written

$$
\begin{array}{ccccc}
\frac{\partial \mathbf{u}}{\partial t}= & -u \cdot \nabla u-w \frac{\partial \mathbf{u}}{\partial z}-f \mathbf{k} \times \mathbf{u}-\frac{1}{\rho_{0}} \nabla p \\
\text { I } & \text { II } \quad \text { III } & \text { IV } & \text { V } \\
& +A_{H} \nabla^{2} \mathbf{u}-\frac{\partial \overline{w^{\prime} \mathbf{u}^{\prime}},}{\partial z} & & \\
\text { VI } & \text { VII } &
\end{array}
$$

where $\mathbf{k}$ is a unit vertical vector, $\rho_{0}$ a representative density, $f$ is the Coriolis parameter, and $\times$ denotes the cross product. Respectively, $\nabla$ and $\nabla^{2}$ are the gradient and Laplacian operators. Here, term I represents local tendency, term II is the horizontal advection, term III the vertical advection, term IV the Coriolis force, term $\mathrm{V}$ is the pressure gradient, term VI is horizontal mixing [where $A_{H}$ is the grid-dependent mixing coefficient described in Wang et al. (2003)], and term VII is vertical mixing, which has contributions from boundary layer turbulence and cumulus mixing (Tiedke 1989). Analysis of the budget terms showed that the pressure gradient, vertical mixing, and horizontal advection terms dominated the budget, as shown in Table 1.

In Fig. 8 the dominant terms of the momentum budget are shown as vectors comprising the $u$ terms and the $v$ terms, at the lowest model level. The pressure gradient term (Fig. 8a) shows the response of the wind to the surface pressure regression showed in Fig. 4b. In contrast the vertical mixing term (Fig. 8b) is directed roughly opposite to that of the pressure gradient and hence appears to act as a drag on the pressure-driven flow. This is consistent with the momentum flux vectors presented in Fig. 7 because the vertical mixing term is equal to minus the vertical derivative of the momentum flux, from (2), and the momentum flux becomes more southeasterly with height over warm SST (and more northwesterly with height over cold SST). The horizontal advection (Fig. 8c) is somewhat weaker, but tends to strengthen the trade winds to the north and west of warm SST, and weakens them to the south and east.

Since the pressure and vertical mixing terms are almost equal and opposite at the lowest level, the horizontal advection is important in determining the total tendency. For the $U$ momentum balance, Fig. $8 \mathrm{~d}$ shows that at $2^{\circ} \mathrm{N}$, to the west (east) of the warm SST at $120^{\circ} \mathrm{W}$, the combination of pressure gradient and vertical mixing, shown as open circles, is forcing weak eastward (westward) acceleration; however, the total tendency with advection included, shown as filled symbols, indicates a westward (eastward) acceleration. For the $V$ momentum balance (Fig. 8e), the combination of pressure and vertical mixing is a weak southward (northward) tendency to the west (east) of the warm SST at $120^{\circ} \mathrm{W}$; however, the additional effect of horizontal advection here acts to force a total tendency, which is northward (southward) to the west (east) of $121.5^{\circ} \mathrm{W}$. Noting that the TIWs propagate to the west with time, so that positions just west (east) of the warm SST at $120^{\circ} \mathrm{W}$ are warming (cooling), it can be seen that the total tendencies in (Figs. 8d,e) are consistent with the observations of northwestward flow over warm SST and southeastward flow over cold SST.

Vertical sections of the dominant $u$ and $v$ momentum budget terms at $2^{\circ} \mathrm{N}$ are presented in Fig. 9. In the $u$ momentum budget the pressure gradient (Fig. 9a) and vertical mixing (Fig. 9c) tend to change sign with height. This may have been expected from the discussion earlier on the vertical variation of the flux terms and the secondary circulation. From the surface to around $\sigma=0.95$ these two terms are almost equal and opposite, and the horizontal advection has smaller magnitude (Fig. 9e). Between $\sigma=0.95$ and $\sigma=0.9$ the horizontal advection becomes comparable in magnitude to the other two terms. Above $\sigma=0.9$ the vertical mixing and pressure gradient show the same sign of tendency and are balanced by the horizontal advection. (It is likely that cloud mixing effects are also important in this region.)

In the $v$ momentum budget the balance near the surface is similar to that of the $u$ momentum. However, above $\sigma=0.95$ the pressure gradient term is weak (Fig. 9b) and the primary balance appears to be between vertical mixing (Fig. 9d) and horizontal advection (Fig. 9f).

\section{Discussion and conclusions}

This paper has sought to elucidate the processes leading to a PBL response to oceanic TIWs using a regional climate model. The main processes examined were the vertical mixing, horizontal advection, and the perturbation pressure gradient induced by the SST changes.

Previous studies have used the relative phasing of 
a)

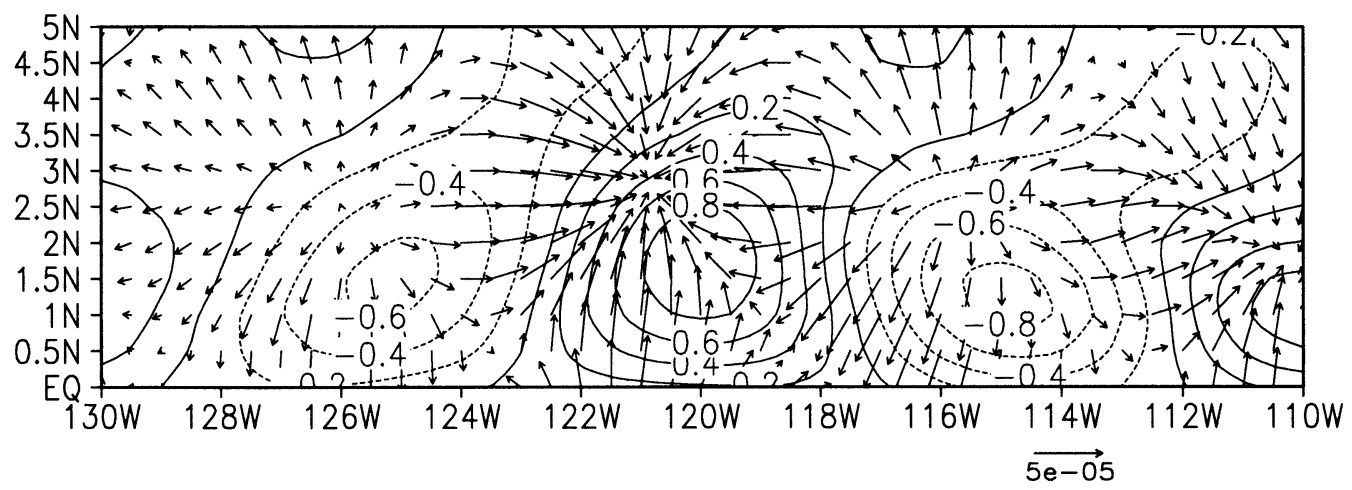

b)

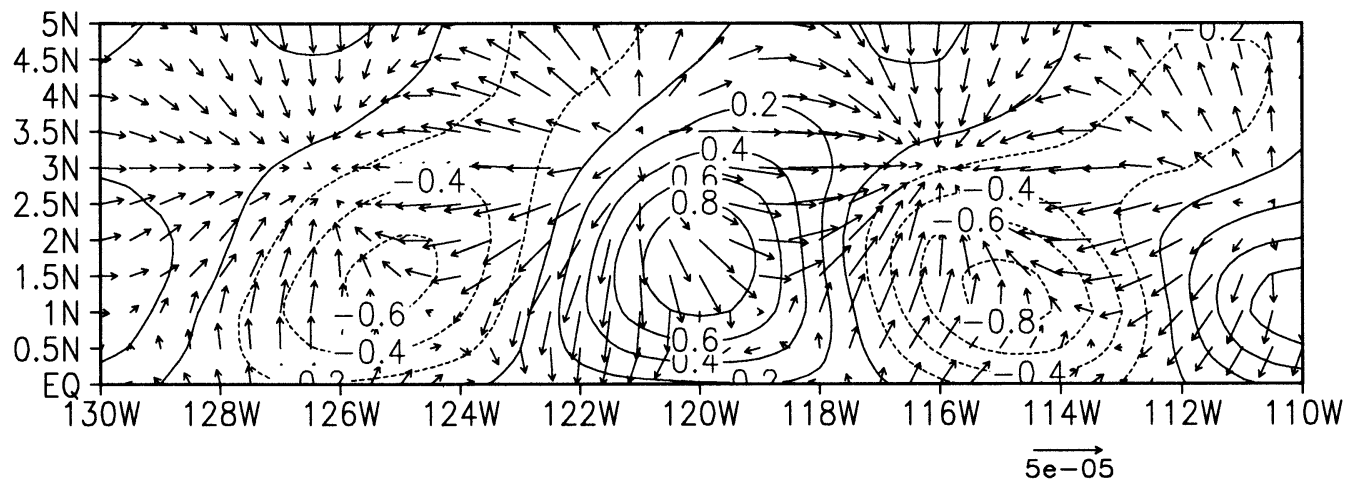

c)

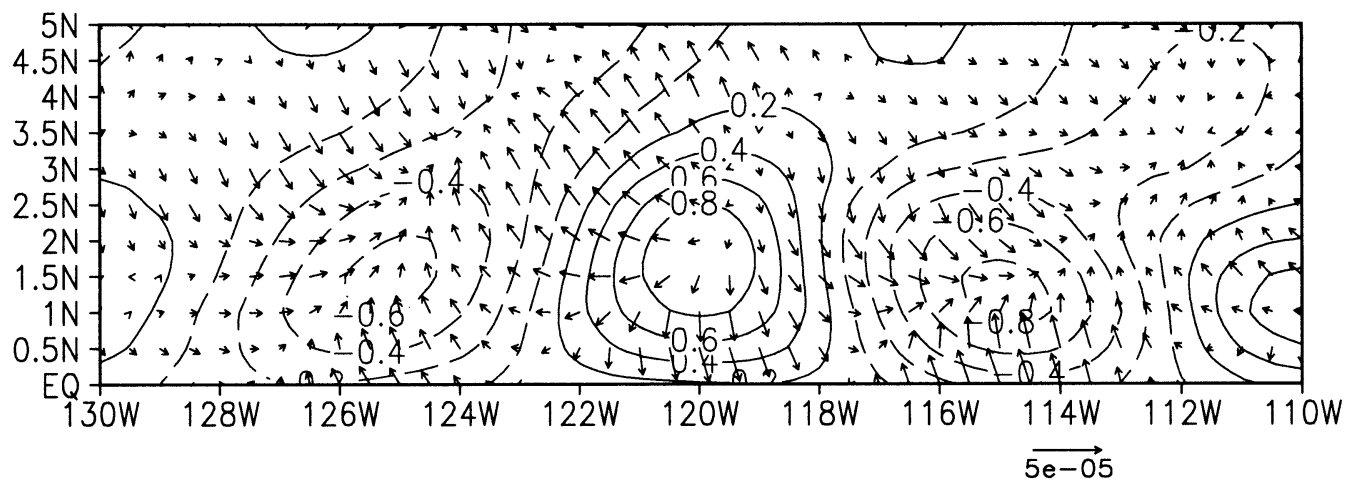

FIG. 8. (a)-(c) Terms in the budget equation for momentum, at bottom model level, regressed onto SST. The terms are shown as vectors, while the regression coefficient of SST is overlaid as contours for reference. Units are $\mathrm{m} \mathrm{s}^{-2} \mathrm{~K}^{-1}$. Surface distributions of (a) pressure gradient, (b) vertical mixing, (c) horizontal advection. (d), (e) Longitude section at $2^{\circ} \mathrm{N}$ showing combined terms in the (d) $U$ momentum budget and (e) $V$ momentum budget. The combined effects of pressure gradient and vertical mixing (line with open circles) and the total tendency (dashed line with filled symbols) are shown.

SST and wind velocity to infer which of the two mechanisms is dominant (HMW; Hashizume et al. 2001), but our modeling results indicate that this method may be unreliable because of the thermal and moisture advection by the mean wind. In the present model, the pressure driving is dominant, but the wind speed and SST are still roughly in phase.

Vertical mixing is still important in driving the latent and sensible heat fluxes, which are higher over warm SST than over cold SST. The increased fluxes over warm
SST are due to reduced static stability and stronger winds. The heat or buoyant fluxes change the atmospheric stratification throughout the PBL, leading to a deeper mixed layer over warm water and a more stable atmosphere over cold SST, as predicted by HMW. The mixed layer is only a few hundred meters deep, in contrast to the 2 or $3 \mathrm{~km}$ quoted by LN. The heat fluxes and consequent changes in atmospheric air temperature and water vapor give rise to perturbation pressure centers and thermally direct circulation cells. The impor- 
d)

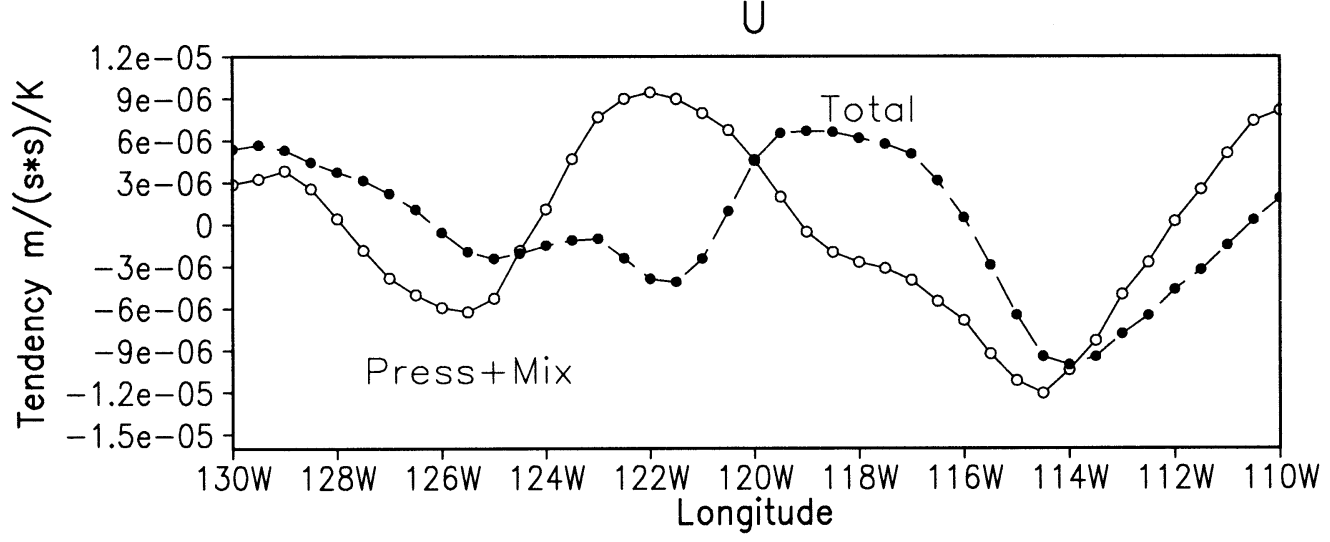

e)

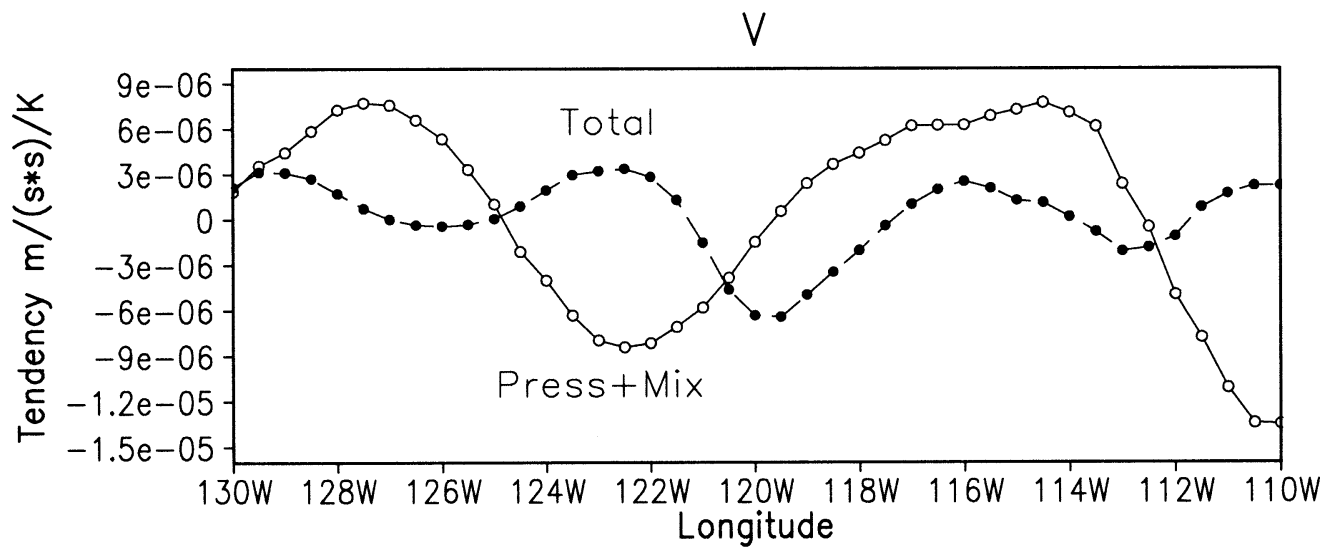

FIG. 8. (Continued)

tance of advection by the mean flow in our model means that the pressure anomalies are located downstream of the SST anomalies, in contrast to the collocation assumed by LN. The pressure gradient in the current model then drives the stronger winds over warm SST, weaker winds over cold SST, which acts as a feedback onto the surface stress field and thus modulates the mixing. As HMW predicted, there is a reduction in wind shear over the warm water (lowest $500 \mathrm{~m}$ in Fig. $5 b)$ but this appears to be a consequence of the circulation cell and pressure gradient driving rather than the vertical mixing.

TABLE 1. Standard deviations of the regression of the momentum tendency terms onto SST at $120^{\circ} \mathrm{W}, 2^{\circ} \mathrm{N}$. The standard deviations for the lower PBL (chosen here as up to $\boldsymbol{\sigma}=0.98$ ) and for the upper PBL (from $\boldsymbol{\sigma}=0.964$ to $\boldsymbol{\sigma}=0.892$ ) were computed for a section at $2^{\circ} \mathrm{N}, 110^{\circ}-130^{\circ} \mathrm{W}$. The different terms are defined in the text (section $4 \mathrm{~b}$ ).

\begin{tabular}{|c|c|c|c|c|c|c|c|}
\hline \multicolumn{8}{|l|}{$U$ momentum } \\
\hline Terms in $10^{-6} \mathrm{~m} \mathrm{~s}^{-2}$ & I & II & III & IV & $\mathrm{V}$ & VI & VII \\
\hline Lower PBL & 5.4 & 8.1 & 1.1 & 1.2 & 18.7 & 1.1 & 19.1 \\
\hline Upper PBL & 6.9 & 7.7 & 4.3 & 1.1 & 7.1 & 1.3 & 5.7 \\
\hline \multicolumn{8}{|l|}{$V$ momentum } \\
\hline Terms in $10^{-6} \mathrm{~m} \mathrm{~s}^{-2}$ & I & II & III & IV & V & VI & VII \\
\hline Lower PBL & 3.8 & 8.7 & 1.5 & 1.2 & 17.1 & 1.0 & 18.5 \\
\hline Upper PBL & 3.6 & 8.4 & 3.2 & 1.1 & 9.4 & 1.5 & 7.0 \\
\hline
\end{tabular}


a)

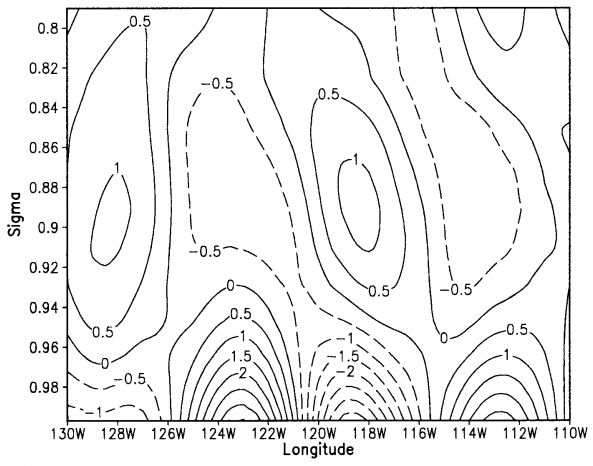

c)

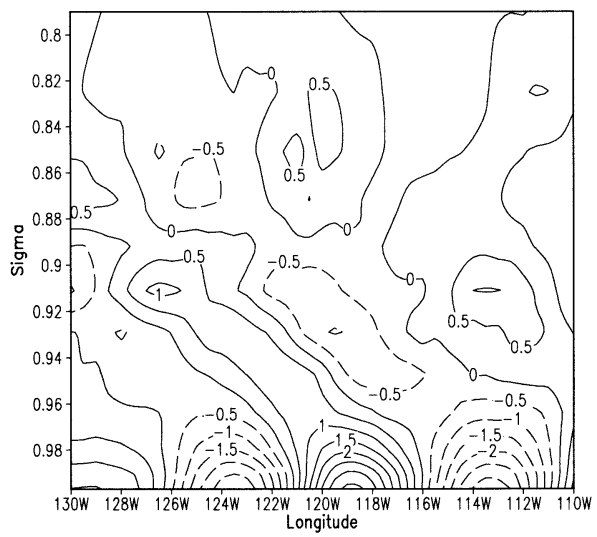

e)

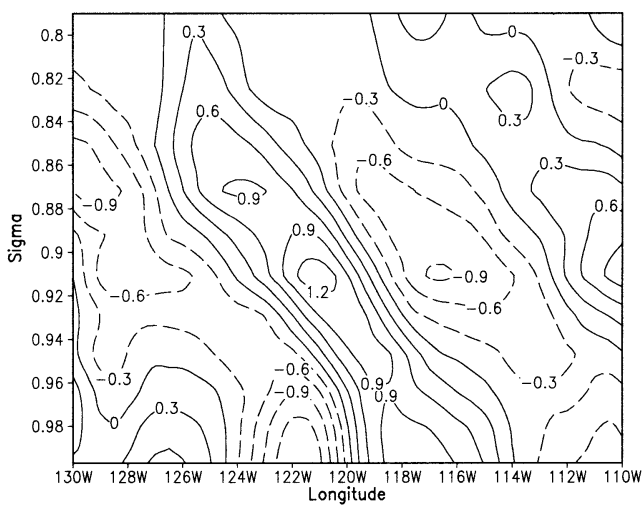

b)

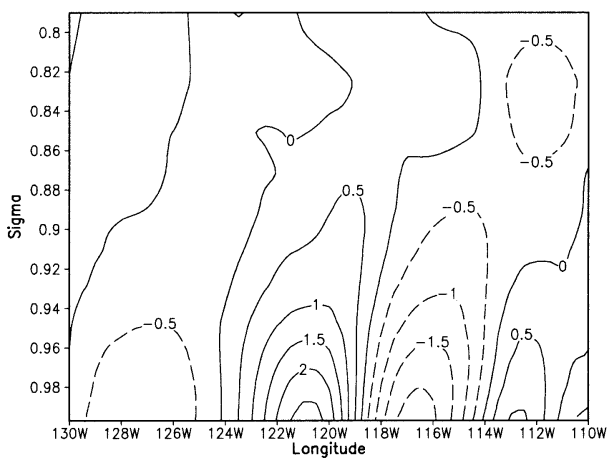

d)

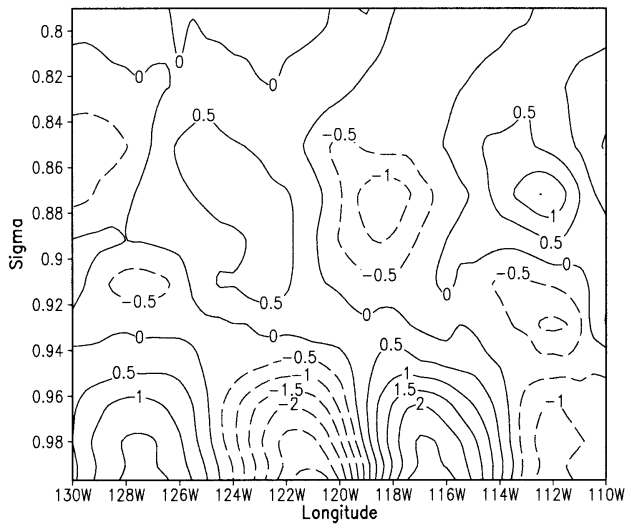

f)

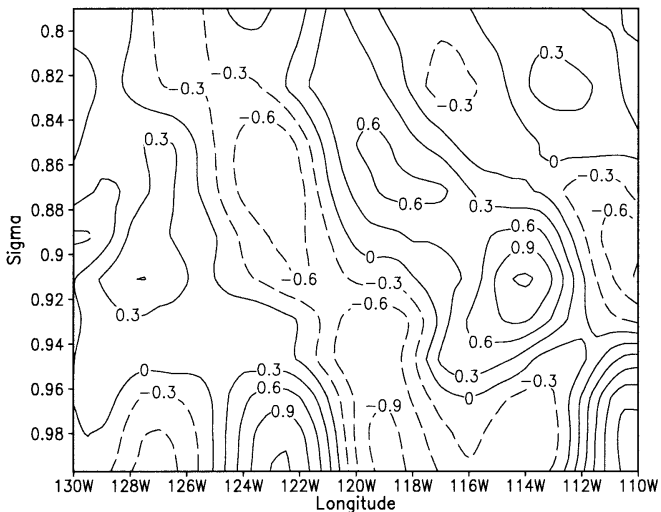

FIG. 9. Vertical cross sections at $2^{\circ} \mathrm{N}$ of terms in the momentum budget equations, regressed and filtered. (a) For $U$ momentum, the pressure gradient term; (b) $V$ momentum, the pressure gradient term. (c) For $U$ momentum, the vertical mixing term; (d) $V$ momentum, the vertical mixing term. (e) For $U$ momentum, the horizontal advection term; (f) $V$ momentum, the horizontal advection term. Units are $\mathrm{m} \mathrm{s}^{-2} \mathrm{~K}^{-1}$.

Analysis of the perturbation momentum budgets showed that near the surface the pressure gradient force and vertical mixing were the dominant terms, with a weaker but significant contribution from horizontal advection. The vertical mixing acted as a drag on the pressure-driven flow particularly in the lowest $500 \mathrm{~m}$. Higher in the PBL the forcing from the pressure gradient and vertical mixing reversed in sign and became weaker, and horizontal advection became more important.
Where possible, satellite observations have been compared with the model simulations to allow an assessment of the model performance. The model well simulates the response of the $10-\mathrm{m}$ neutral winds and the water vapor field to the TIWs, particularly north of the cold tongue. However the stronger dependence of wind perturbation on SST that was observed south of the equator was not reproduced in the model. Reasons for this are as yet unknown. 
The present model study suggests a possible mechanism by which PBL processes adjust the wind, temperature, and water vapor fields in response to SST gradients in TIWs, and the simulations are reasonably consistent with observations from satellite and in situ data. However some processes were not considered in the present simulation that need to be addressed in future. For instance, observations in Hashizume et al. (2002) demonstrate the presence of much stronger trade wind temperature inversions in the TIW region than are simulated in the model. They found that composite profiles of observations over warm SST showed large inversion heights $(1400 \mathrm{~m})$ relative to those over cold SST (1000 $\mathrm{m})$. The effect of this change in inversion height on the hydrostatic surface pressure was to counter the hydrostatic effect of near-surface atmospheric warming or cooling, thus possibly modifying the pressure gradient effect discussed in this paper.

Acknowledgments. The TMI data (version 2) are obtained from the web site of Remote Sensing Systems (http://www.remss.com). The QuikSCAT/SeaWinds data are obtained from the Web site of the Jet Propulsion Laboratory (http://airsea-www.jpl.nasa.gov/seaflux). We would like to thank Bunmei Taguchi for preparing the QuikSCAT data. This study is supported in part by NASA (Grant NAG-10045 and JPL Contract 1216010), NOAA (NA17RJ1230), and NSF (ATM01-04468). The IPRC is partly supported by the Frontier Research System for Global Change.

\section{APPENDIX A}

\section{The Bulk Flux Representation}

In the Reg-CM, aerodynamic bulk flux formulas are used to estimate air-sea exchange within the constant flux or surface layer. In this layer the surface sensible heat $\left.\mathrm{SF}\right|_{\text {surf }}$ and latent heat $\left.\mathrm{LF}\right|_{\text {surf }}$ fluxes are given by (Stull 1988):

$$
\begin{aligned}
\left.\mathrm{SF}\right|_{\text {surf }} & \equiv \rho c_{p} \overline{w^{\prime} \theta^{\prime}}=-\rho c_{p} u^{*} \theta^{*}=-\rho c_{p} C_{H} U\left(T_{s}-T_{a}\right) \\
\left.\mathrm{LF}\right|_{\text {surf }} & \equiv \rho L_{v} \overline{w^{\prime} q^{\prime}}=-\rho L_{v} u^{*} q^{*} \\
& =-\rho L c_{v} C_{H} U\left(q_{s}-q_{a}\right),
\end{aligned}
$$

where the convention here is that positive flux denotes heat given from the ocean to the atmosphere. Here, $u^{*}$ is the wind friction velocity and $\theta^{*}$ and $q^{*}$ are potential temperature and moisture scales. It has been assumed that the drag coefficient for heat and moisture have the same value, $C_{H}$. The values $T$ and $q$ are temperature and specific humidity, and subscript $a$ denotes in the constant flux layer and subscript $s$ just above the surface. Quantities with overbars denote the turbulent correlations, and other terms are defined in the main text. The drag coefficients and scales of moisture and temperature are computed using the Tropical Ocean Global Atmosphere Coupled Ocean-Atmosphere Response Experi- ment (TOGA COARE v2.6) algorithms detailed by Fairall et al. (1996).

The wind stress or momentum flux $\tau=\left(\tau_{x}, \tau_{y}\right)$, is written

$$
\begin{aligned}
\tau & \equiv \rho\left(u^{*}\right)^{2}=\rho C_{D} U^{2}=\rho C_{\mathrm{DN}} U_{10}^{2} \\
\tau_{x} & \equiv-\rho \overline{u^{\prime} w^{\prime}}=\rho C_{D} u U=\rho C_{\mathrm{DN}} u_{10} U_{10}=-\left.\mathrm{UF}\right|_{\text {surf }} \\
\tau_{y} & \equiv-\rho \overline{v^{\prime} w^{\prime}}=\rho C_{D} v U=\rho C_{\mathrm{DN}} v_{10} U_{10}=-\left.\mathrm{VF}\right|_{\text {surf }},
\end{aligned}
$$

where $C_{D}$ is the drag coefficient that depends on wind speed $U$ and static stability (Fairall et al. 1996), $U_{10}$ is the neutral equivalent wind at $10 \mathrm{~m}$, and $C_{\mathrm{DN}}$ is the neutral drag coefficient at $10 \mathrm{~m}$ that depends only on wind speed. The drag coefficient $C_{D}$ may be defined for any height $z$, and it is related to $C_{\mathrm{DN}}$ by the following expression:

$$
C_{D}(z)=\frac{C_{\mathrm{DN}}}{\left\{1+\frac{1}{\kappa} C_{\mathrm{DN}}^{1 / 2}\left[\ln \left(\frac{z}{10}\right)-\psi_{M}\right]\right\}^{2}},
$$

where $\kappa$ is the von Kármán constant, and $\psi_{M}$ is the stability function that depends on the height, friction velocity, and the static stability $\left(T_{s}-T_{a}\right)$ (i.e., on $z$, scaled by the Monin-Obukhov length) and is calculated using the Fairall et al. (1996) algorithms.

\section{APPENDIX B}

\section{The Direct Effect of Surface Stability on the Wind Stress Fields}

This appendix describes two simple surface layer experiments, which were designed to determine the direct influence of static stability on the TIW-related wind stress or $U_{10}$ variations. These experiments are performed external to the model, but use the same surface flux code as the model.

Changes in $T_{s}-T_{a}$ due to TIWs alter the static stability of the near-surface layer and hence affect the stress. However, changes in the background wind speed $U$ above the surface layer will also lead to changes in stress, independent of changes in stability. These factors are contained in (A2), noting that $C_{D}$ depends on both wind speed and static stability.

Two experiments were conducted to test whether changes in static stability or in the background wind flow dominate the variations in wind stress associated with TIWs. In experiment $1, U_{10}$ is calculated by assuming the background wind $U\left(z=z_{0}\right)$ at a particular level at the top of the surface layer, $z_{0}$, does not change, but the static stability $T_{s}-T_{a}$ does. The surface layer algorithms of Fairall et al. (1996) are applied to compute the drag coefficient $C_{D}(z)$ at $z=z_{0}$, and the wind stress $\tau$. Then the neutral drag coefficient at $10 \mathrm{~m}, C_{\mathrm{DN}}$, is calculated from (A3), and hence $U_{10}$ from (A2). In ex- 

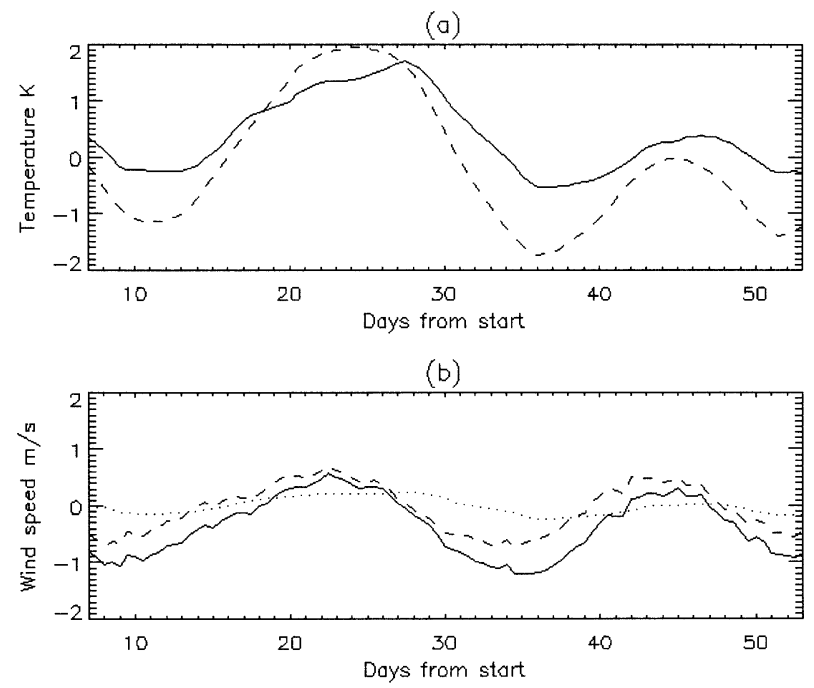

FIG. B1. Effect of static stability on near-surface winds, at $2^{\circ} \mathrm{N}$, $120^{\circ} \mathrm{W}$. Day 0 refers to 1 Sep 1999 . (a) Solid line represents the model-predicted air-sea temperature difference (air temperature at 10 $\mathrm{m}$ ); dashed line represents SST. (b) Neutral equivalent 10-m wind speed fluctuations. Solid line represents full model predictions. Dotted line represents experiment 1 (see text). Dashed line represents experiment 2 (see text). The data have been smoothed with a running mean over 7 days. (a), (b) The solid lines in have been filtered by removing a $12^{\circ}$ running mean. The dashed and dotted lines have had the time mean removed.

periment 2, the background wind at $z=z_{0}$ is allowed to change but $T_{s}-T_{a}$ is kept constant. Again the surface layer theory is applied between $z=0$ and $z=z_{0}$ to derive $U_{10}$.

The experiments use model data from a representative location along the TIW propagation path $\left(2^{\circ} \mathrm{N}, 120^{\circ} \mathrm{W}\right)$, and at the lowest model level $z_{0}=z_{b}$ (on average at 25 - $\mathrm{m}$ height). In experiment 1 , the mean wind speed is $U=7.8 \mathrm{~m} \mathrm{~s}^{-1}$ and the time-varying $T_{s}-T_{a}$ output from the model is shown in Fig. B1a. Note that the conditions are generally unstable except during times of coldest SST in the TIWs. [The range of $T_{s}-T_{a}$ (from -0.4 to $1.6 \mathrm{~K}$ ) is similar to that observed by Anderson (2001).] Experiment 2 used the time-varying model output wind speed at $z_{0}=z_{b}$ to represent $\mathrm{U}$, and a time mean value of $T_{s}-T_{a}=0.7 \mathrm{~K}$.

The results of the experiments are shown in Fig. B1b. In experiment 1 , the predicted variation of $U_{10}$ is small (dotted line in Fig. B1b) and has a standard deviation of $0.14 \mathrm{~m} \mathrm{~s}^{-1}$. For comparison, the actual model prediction of $U_{10}$ (which includes full model physics) has standard deviation 0.52 (solid line in Fig. B1b). The results from experiment 2 (dashed line in Fig. B1b) show a greater fluctuation, with a standard deviation of 0.43 , closer to the full model value.

These results suggest that the contribution of static stability effects alone to $U_{10}$ is quite small, and that the circulation in the PBL above the surface layer, which gives rise to the wind speed variations at $z=z_{0}$, is more important. It may be questioned whether the choice of $z_{0}=z_{b}=25 \mathrm{~m}$ is a good one for these computations, as the surface layer may extend deeper into the PBL, and the experiments were repeated for the next model level, so that $z_{0}=78 \mathrm{~m}$ height. These results showed a slightly larger standard deviation for experiment 1 $(0.26)$ and little difference in experiment 2. It may still be concluded that the major contributor for variations in $U_{10}$ (equivalently, in wind stress) is not primarily from static stability but instead from perturbations of PBL wind by factors that are discussed in sections 3 and 4 .

\section{REFERENCES}

Anderson, S. P., 2001: On the atmospheric boundary layer over the equatorial front. J. Climate, 14, 1688-1695.

Chelton, D., and Coauthors, 2001: Observations of coupling between surface wind stress and sea surface temperature in the eastern tropical Pacific. J. Climate, 14, 1479-1498.

Chou, M., M. J. Suarez, C.-H. Ho, M. M.-H. Yan, and K.-T. Lee, 1998: Parameterizations for cloud overlapping and shortwave single-scattering properties for use in general circulation and cloud ensemble models. J. Climate, 11, 202-214.

Contreras, R. F., 2002: Long-term observations of tropical instability waves. J. Phys. Oceanogr., 32, 2715-2722.

Cronin, M. F., S.-P. Xie, and H. Hashizume, 2003: Barometric pressure variations associated with eastern Pacific tropical instability waves. J. Climate, 16, 3050-3057.

Detering, H. W., and D. Etling, 1985: Application of the E- $\varepsilon$ turbulence model to the atmospheric boundary layer. Bound.-Layer Meteor., 33, 113-133.

Dickinson, R. E., A. Henderson-Sellors, and P. J. Kennedy, 1993: Biosphere-atmosphere transfer scheme (BATS) version 1e as coupled to the NCAR Community Climate Model. NCAR Tech. Note NCAR/TN-387+STR, 72 pp.

Edwards, J. M., and A. Slingo, 1996: Studies with a flexible new radiation code. 1: choosing a configuration for a large-scale model. Quart. J. Roy. Meteor. Soc., 122, 689-719.

Fairall, C. W., E. F. Bradley, D. P. Rogers, J. B. Edson, and G. S. Young, 1996: Bulk parameterization of air-sea fluxes for Tropical Ocean-Global Atmosphere Coupled-Ocean Atmosphere Response Experiment. J. Geophys. Res., 101, 3747-3764.

Gregory, D., J.-J. Morcrette, C. Jakob, A. C. M. Bejiaars, and T. Stockdale, 2000: Revision of convection, radiation and cloud schemes in the ECMWF integrated forecast system. Quart. J. Roy. Meteor. Soc., 126, 1685-1710.

Hashizume, H., S.-P. Xie, W. T. Liu, and K. Takeuchi, 2001: Local and remote response to tropical instability waves: A global view from space. J. Geophys. Res., 106, 10 173-10 185.

- _ - M. Fujiwara, M. Shiotani, T. Watanabe, Y. Tanimoto, W. T. Liu, and K. Takeuchi, 2002: Direct observations of inversioncapped boundary layer response to slow variations in sea surface temperature on the Pacific equatorial front. J. Climate, 15, 33793393.

Hayes, S. P., M. J. McPhaden, and J. M. Wallace, 1989: The influence of sea surface temperature on surface wind in the eastern equatorial Pacific: Weekly to monthly variability. J. Climate, 2, 15001506.

Holton, J. R., 1992: An Introduction to Dynamical Meteorology. 3d ed. Academic Press, $511 \mathrm{pp}$.

IDL (Interactive Data Language), 1995: Users guide and reference guide. RSI

Kalnay, E., and Coauthors, 1996: The NCEP/NCAR 40-Year Reanalysis Project. Bull. Amer. Meteor. Soc., 77, 437-471.

Langland, R. H., and C.-S. Liou, 1996: Implementation of an E- $\varepsilon$ parameterization of vertical subgrid-scale mixing in a regional model. Mon. Wea. Rev., 124, 905-918.

Legeckis, R., 1977: Long waves in the eastern equatorial Pacific 
Ocean: A view from a geostationary satellite. Science, 197, 1179-1181.

Lindzen, R. S., and S. Nigam, 1987: On the role of sea surface temperature gradients in forcing low-level winds in the Tropics. J. Atmos. Sci., 44, 2418-2436.

Liu, W. T., X. Xie, P. S. Polito, S.-P. Xie, and H. Hashizume, 2000: Atmospheric manifestation of tropical instability waves observed by QuikSCAT and Tropical Rain Measuring Mission. Geophys. Res. Lett., 27, 2545-2548.

Slingo, A., and H. M. Schrecker, 1982: On the shortwave radiative properties of water clouds. Quart. J. Roy. Meteor. Soc., 108, 407-426.

Stull, R. B., 1988: An Introduction to Boundary Layer Meteorology. Kluwer Academic, 666 pp.

Sun, Z., and K. Shine, 1994: Studies of the radiative properties of ice and mixed phase clouds. Quart. J. Roy. Meteor. Soc., 120, 111-137.

_ _ and L. Rikus, 1999: Improved application of exponential sum fitting transmissions to inhomogeneous atmosphere. J. Geophys. Res., 104, 6291-6303.

Thum, N., S. K. Esbensen, D. B. Chelton, and M. J. McPhaden, 2002: Air-sea heat exchange along the northern sea surface temperature front in the eastern tropical Pacific. J. Climate, 15, 33613378.

Tiedtke, M., 1989: A comprehensive mass flux scheme for cumulus parameterization in large-scale models. Mon. Wea. Rev., 117, $1779-1800$.

Wallace, J. M., T. P. Mitchell, and C. Deser, 1989: The influence of sea surface temperature on surface wind in the eastern equatorial Pacific: Seasonal and interannual variability. J. Climate, 2, 14921499.

Wang, Y., 2001: An explicit simulation of tropical cyclones with a triply nested movable mesh primitive equation model: TCM3. Part 1: Model description and control experiment. Mon. Wea. Rev., 129, 1370-1394.

, 2002: An explicit simulation of tropical cyclones with a triply nested movable mesh primitive equation model: TCM3. Part II: Model refinements and sensitivity to cloud microphysics parameterization. Mon. Wea. Rev., 130, 3022-3036.

—- O. L. Sen, and B. Wang, 2003: A highly resolved regional climate model (IPRC-RegCM) and its simulation of the 1998 severe precipitation event over China. Part I: Model description and verification of simulation. J. Climate, 16, 1721-1738.

Wentz, F. J., C. Gentemann, D. Smith, and D. Chelton, 2000: Satellite measurements of sea surface temperature through clouds. Science, 288, 847-850.

Xie, S.-P., M. Ishiwatari, H. Hashizume, and K. Takeuchi, 1998: Coupled ocean-atmospheric waves on the equatorial front. Geophys. Res. Lett., 25, 3863-3866.

Xu, K.-M., and D. A. Randall, 1996: A semiempirical cloudiness parameterization for use in climate models. J. Atmos. Sci., 53, 3084-3102. 